Louisiana State University

LSU Digital Commons

Faculty Publications

Department of Chemistry

$11-16-2005$

\title{
Detection of homocysteine and cysteine
}

\author{
Weihua Wang \\ Louisiana State University \\ Oleksandr Rusin \\ Louisiana State University \\ Xiangyang $\mathrm{Xu}$ \\ Louisiana State University \\ Kyu Kwang Kim \\ Louisiana State University \\ Jorge O. Escobedo \\ Louisiana State University
}

See next page for additional authors

Follow this and additional works at: https://digitalcommons.Isu.edu/chemistry_pubs

\section{Recommended Citation}

Wang, W., Rusin, O., Xu, X., Kim, K., Escobedo, J., Fakayode, S., Fletcher, K., Lowry, M., Schowalter, C., Lawrence, C., Fronczek, F., Warner, I., \& Strongin, R. (2005). Detection of homocysteine and cysteine. Journal of the American Chemical Society, 127 (45), 15949-15958. https://doi.org/10.1021/ja054962n

This Article is brought to you for free and open access by the Department of Chemistry at LSU Digital Commons. It has been accepted for inclusion in Faculty Publications by an authorized administrator of LSU Digital Commons. For more information, please contact ir@lsu.edu. 


\section{Authors}

Weihua Wang, Oleksandr Rusin, Xiangyang Xu, Kyu Kwang Kim, Jorge O. Escobedo, Sayo O. Fakayode, Kristin A. Fletcher, Mark Lowry, Corin M. Schowalter, Candace M. Lawrence, Frank R. Fronczek, Isiah M. Warner, and Robert M. Strongin 


\title{
Detection of Homocysteine and Cysteine
}

\author{
Weihua Wang, Oleksandr Rusin, Xiangyang Xu, Kyu Kwang Kim, Jorge O. Escobedo, Sayo \\ O. Fakayode, Kristin A. Fletcher, Mark Lowry, Corin M. Schowalter, Candace M. Lawrence, \\ Frank R. Fronczek, Isiah M. Warner, and Robert M. Strongin \\ Department of Chemistry, Louisiana State University, Baton Rouge, Louisiana 70803
}

Robert M. Strongin: rstrong@lsu.edu

\begin{abstract}
At elevated levels, homocysteine (Hcy, $\mathbf{1})$ is a risk factor for cardiovascular diseases, Alzheimer's disease, neural tube defects, and osteoporosis. Both $\mathbf{1}$ and cysteine (Cys, $\mathbf{3}$ ) are linked to neurotoxicity. The biochemical mechanisms by which $\mathbf{1}$ and $\mathbf{3}$ are involved in disease states are relatively unclear. Herein, we describe simple methods for detecting either Hcy or Cys in the visible spectral region with the highest selectivity reported to date without using biochemical techniques or preparative separations. Simple methods and readily available reagents allow for the detection of Cys and Hcy in the range of their physiologically relevant levels. New HPLC postcolumn detection methods for biological thiols are reported. The potential biomedical relevance of the chemical mechanisms involved in the detection of $\mathbf{1}$ is described.
\end{abstract}

\section{Introduction}

\section{Homocysteine and Cysteine in Human Health}

Elevated plasma homocysteine (Hcy, 1) levels are associated with increased risk of myocardial infarction, stroke, and venous thromboembolism. ${ }^{1}$ Hyperhomocysteinemia has also been linked to increased risk of Alzheimer's disease, ${ }^{2}$ neural tube defects, ${ }^{3}$ complications during pregnancy, ${ }^{4}$ inflammatory bowel disease, ${ }^{5}$ and osteoporosis. ${ }^{6}$

The role of Hcy in disease is unclear. After many years of study and impressive progress, it is still not yet known if Hcy causes disease, is a consequence of it, or is simply a biomarker. ${ }^{1 \mathrm{~b}}$ There is an ongoing effort in the biomedical community involving the study of hyperhomocysteinemia. ${ }^{1 b}$

There is a compelling case for detecting and treating hyperhomocysteinemia in patients with a history of premature cardiovascular disease, stroke, or venous thromboembolism. ${ }^{\text {b }}$ Hcy also is of interest as an analyte for the screening of inborn errors of methionine metabolism. Hcy monitoring is also useful in testing for folate and vitamin $\mathrm{B}_{12}$ deficiency. ${ }^{\mathrm{b}}$

Homocystinurics have up to $500 \mu \mathrm{M}$ levels of total plasma Hcy (tHcy, free thiol plus disulfide), including ca. $100 \mu \mathrm{M}$ of freely circulating thiol. Patients with this disorder are

\footnotetext{
(C) 2005 American Chemical Society

Correspondence to: Oleksandr Rusin; Robert M. Strongin, rstrong@ lsu . edu.

Supporting Information Available: ${ }^{1} \mathrm{H}$ NMR, ${ }^{13} \mathrm{C}$ NMR, FTIR, and MALDI-TOF spectra of $\mathbf{6 b}$; ORTEP drawings for $\mathbf{6 a}$ and $\mathbf{6 b}$; CIF files for $6 \mathbf{a}$ and $6 \mathrm{~b}$; UV - vis data for $6 \mathbf{a}, 6 \mathbf{b}, 8 \mathbf{a}, 8 \mathrm{~b}, 8 \mathbf{c}$ and 11 under various experimental conditions; fluorescence data for $6 \mathbf{a}$, $\mathbf{6 b}$, and $\mathbf{1 1}$ under different experimental conditions; chromatogram for Cys; ${ }^{31} \mathrm{P}$ NMR spectra of $\mathrm{PPh}_{3}$ in the absence and presence of 11; MALDI-TOF spectra for the reaction mixture of $\mathbf{1 1}$ and Hcy with and without matrix; ${ }^{1} \mathrm{H}$ NMR spectra of $8 \mathbf{c}$ and $8 \mathbf{c}$ in the presence of Cys or Hcy. This material is available free of charge via the Internet at http://pubs.acs.org.
} 
prone to severe neurodegeneration and mental retardation, if left untreated. Frequent Hcy monitoring is apparently important in such cases. ${ }^{1,7}$

Unlike Hcy, the relatively more common biological thiols, such as glutathione (GSH, 2), are typically associated with beneficial antioxidant activity. It is therefore important to understand the differences between the fundamental chemistry of Hcy, its derivatives, and other biothiols.

Elevated levels of both Hcy and cysteine (Cys, $\mathbf{3}$ ) have been associated with neurotoxicity. In the case of Cys, this has been demonstrated in vivo in animals with immature blood brain barriers and in cultured neurons in vitro. ${ }^{8}$ Additionally, Cys-induced hypoglycemic brain damage has been studied as an alternative mechanism to excitotoxicity. ${ }^{9}$ The reasons for these effects on the brain are not completely clear.

Cys can be obtained as the final product of the transsulfuration pathway through Hcy metabolism. The exceptionally poor water solubility of the disulfide cystine reduces its excretion. It therefore accumulates either in urine (leading to cystinuria) ${ }^{10}$ or in various organs of the body (e.g., the kidneys). ${ }^{11}$ Low levels of Cys are associated with slowed growth, hair depigmentation, edema, lethargy, liver damage, muscle and fat loss, skin lesions, and weakness. ${ }^{12}$ Cys detection is thus of interest.

\section{Current State-of-the-Art in Biothiol Analysis}

The determination of specific thiols is often carried out in conjunction with separations. ${ }^{13}$ Derivatization with fluorescent reagents is typically used. Most of these reagents possess universal electrophilic alkylating groups for reaction with sulfhydrils. They are not selective and have several drawbacks and limitations (Table 1). ${ }^{14,15}$ There are nearly 50 thiol-reactive reagents currently sold by Molecular Probes, Inc. ${ }^{15 b}$ There is thus great interest in developing agents for detecting biothiols.

Innovative molecular probes for thiols have also been reported in the literature. These include $1,1^{\prime}$-thiocarbonyl diimidazole, shown to derivatize Cys and penicillamine; however, the adducts are detected at relatively short wavelength. ${ }^{16}$ Other very creative, recently reported reagents promote thiol-induced signaling. ${ }^{17}$

Refsum et al., as well as several others, have made pioneering advances in developing HPLC assays toward Hcy and related biothiol analysis. ${ }^{13 \mathrm{~b}}$ These methods are used in largescale population studies that have been ongoing for 2 decades. ${ }^{13 \mathrm{~b}}$ Refsum et al. addressed the issues of removing excess mono-bromobimane and other (unidentified) fluorescent impurities prior to HPLC analyses in 1989. ${ }^{18}$ They used a chromatographic "heart-cut," with a column switching device and two-solvent delivery system. They later devised a convenient automated system requiring less tedium, instrumental manipulation, and wear as compared to their 1989 method. ${ }^{19}$ The retention times of the fluorescent impurity peaks caused by the monobromobimane are highly $\mathrm{pH}$-sensitive. The method works well on the basis of precise control of mobile phase acidity and the relatively high fluorescence of the bimane - thiol adducts.

The highly useful commercial immunoassays (e.g., the fluorescence polarization immunoassay run on Abbott's Imx and AxSYM platforms ${ }^{20}$ ) monitor one analyte at a time and utilize relatively fragile biological materials. In certain studies, interlaboratory imprecision with immunoassay methods has been reported. ${ }^{21}$ In addition, fluorescence immunoassay reagents are relatively very expensive. ${ }^{15}$ 
As stated by Refsum et al. in their comprehensive 2004 review coauthored by a group of the world's leading experts in this field, many analytical methods afford results that do not fulfill baseline bias and imprecision criteria. ${ }^{13 \mathrm{~b}}$ Interlaboratory and inter- and intrapatient errors in Hcy and biological thiol assays persist. There is a need for standardization. HPLC monitoring with a universal thiol-derivatizing reagent affords simultaneous monitoring of thiols, but it requires skilled staff and is labor intensive and throughput may be low. ${ }^{13 \mathrm{~b}}$

Highly selective probes for Hcy and Cys are being developed in our lab as potentially useful new detection agents. ${ }^{22}$ The selective colorimetric and fluorimetric detection of Cys and Hcy in natural media is reported herein. New HPLC methods are also described. The study of chemoselective probes promotes further understanding of the unique organic and bioorganic chemistry of Hcy and Cys.

\section{Results and Discussion}

\section{Thiazolidines as Stable, Readily Formed Cys and Hcy Adducts}

It has been known for nearly 80 years that carbonyls react with Cys. ${ }^{23} \mathrm{~N}$-Terminal Cys residues react readily with aldehydes to form thiazolidines. ${ }^{24}$ The products are stable even at slightly acidic $\mathrm{pH}$ in aqueous solvents. Thiazolidine formation has been effectively used in modern ligation reactions. ${ }^{25} \mathrm{~N}$-Teminal oxazolidines (i.e., heterocycles derived from the reaction of serine and aldehydes) are $10^{4}$ times less stable than Cys-derived thiazolidines. ${ }^{25}$

\section{Thiazolidine Reactions for the Detection of Cys and Hcy}

The synthesis of dialdehyde 6a was initially described by Lippard et al. ${ }^{26}$ Compound $6 \mathbf{a}$ as well as monoaldehyde $\mathbf{6 b}$ are synthesized in our lab in one step via a Reimer - Tieman reaction of commercial fluorescein. Single-crystal X-ray structure analysis confirms the structure assignment of $\mathbf{6 a}$ and $\mathbf{6 b}$ (Scheme 1).

Upon addition of Cys or Hcy to a solution of $\mathbf{6 a}$, a solution color change from bright yellow to brownish-orange can be observed. ${ }^{22}$ S Similar color changes are observed on $\mathrm{C}_{18}$-bonded silica. ${ }^{22 a}$ Healthy plasma tHcy concentrations are less than ca. $12-15 \mu \mathrm{M}$. Plasma Cys concentrations are typically $20-30$ times that of Hcy. Our previous studies ${ }^{22 a}$ show that Cys-6a solutions can be monitored in the $10^{-5}-10^{-6} \mathrm{M}$ Cys concentration range. Cys addition to a solution of $\mathbf{6 a}$ produces a $25-\mathrm{nm}$ red shift. $22 \mathrm{a}$ Addition of Cys to solutions of $\mathbf{6 a}$ also results in monitorable fluorescence quenching. ${ }^{22 a}$ The reaction of Cys or Hcy with $6 \mathbf{6}$ affords thiazolidines or thiazinanes, respectively (Cys $\mathbf{7 a}$, Hcy $\mathbf{7 b}$ heterocyclic adducts, Scheme 1). ${ }^{22 a}$ Their structures have been confirmed. ${ }^{22 a}$

UV - vis absorbance spectra of solutions containing 6a and other sulfur-containing compounds (L-methionine, mercaptoethanol, GSH), other amino acids (L-glutamine, L-serine,

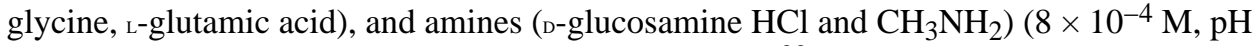
9.5) confirm the high selectivity of $\mathbf{6 a}$ for Cys and Hcy. ${ }^{22 a}$ Solutions containing $\mathbf{6 a}$ and bovine serum albumin or urease likewise exhibit only relatively insignificant absorbance decreases. ${ }^{22 a}$ No red shift occurs upon addition of any of the aforementioned potential interferents, even when added at 10 -fold higher concentrations relative to Cys. ${ }^{22 a}$

Additionally, UV - vis absorbance spectral changes are observed upon adding Cys to human blood plasma samples containing $\mathbf{6 a}$ that are similar to those seen in buffer solution. ${ }^{22 a}$ Fluorescence quenching is also observed upon titrating a solution of $\mathbf{6 a}$ in plasma with Cys and Hcy. ${ }^{22 a}$ Barbas et al. have subsequently used aldehyde-functionalized dyes to promote solution emission intensity increases in response to Cys. ${ }^{17 \mathrm{e}} \mathrm{We}$ find that solutions 
containing $\mathbf{6 a}$ or $\mathbf{6 b}$ exhibit moderately greater fluorescence quenching in response to Cys as compared to Hcy. ${ }^{27}$

\section{Highly Selective Colorimetric Cys Detection Using a Commercially Available Aldehyde}

Commercially available 4-nitrocinnamaldehyde (8a), cinnamaldehyde (8b), and 4- $(N, N-$ dimethylamino) cinnamaldehyde (8c) are a series of prototypical a, $\beta$-unsaturated aldehyde substrates with decreasing electrophilicity. Potentially heightened selectivity for Cys over Hcy is predicted. Cys may form generally more favored 5- (or possibly 7-) membered ring heterocycles, as compared to Hcy (6- or possibly 8-membered ring formation, respectively), upon reaction with $a, \beta$-unsaturated aldehydes. ${ }^{28 a}$

The least reactive electrophile, $\mathbf{8 c}$, exhibits the highest Cys selectivity. ${ }^{27}$ A solution color change from yellow to colorless is observed in $10 \mathrm{~min}$ after addition of Cys $\left(1.0 \times 10^{-3} \mathrm{M}\right)$ to a solution of $8 \mathbf{c}\left(1.0 \times 10^{-6} \mathrm{M}\right.$, carbonate buffer, $\left.\mathrm{pH} 9.5\right)$. Hcy did not cause any color change under these conditions (Figure 2).

We observe complete conversion to $9 \mathrm{~b}$ by ${ }^{1} \mathrm{H}$ NMR after $1 \mathrm{~h}$ for the reaction of $\mathbf{C y s}(0.46$ $\mathrm{M})$ and $8 \mathbf{c}\left(3.4 \times 10^{-2} \mathrm{M}\right)$ in $\mathrm{D}_{2} \mathrm{O}(0.5 \mathrm{~mL})$ containing $30 \% \mathrm{NaOD}(0.001 \mathrm{~mL})$ (see Figure S13, Supporting Information). This transformation is confirmed via the disappearance of the aldehyde signal at $9.5 \mathrm{ppm}$ and subsequent appearance of the thiazolidine resonances (proton $b$, Scheme 2) centered at $\delta 6.7 \mathrm{ppm}$. Olefin proton resonance $c$ can be clearly observed (dd, $J=16,8.3 \mathrm{~Hz}, 1 \mathrm{H})$ appearing $0.4 \mathrm{ppm}$ upfield relative to the corresponding resonance in $\mathbf{8 c}$. Under similar conditions, Hcy reacts with $\mathbf{8 c}$ to form imine $9 \mathbf{a}$ in trace amounts as the only observed product by ${ }^{1} \mathrm{H}$ NMR. ${ }^{27}$ The ${ }^{1} \mathrm{H}$ NMR resonance for the Schiff base proton (carbon a, Scheme 2) is centered at $\delta=8.01 \mathrm{ppm}$, in agreement with analogous imine-forming controls using $\mathbf{8 c}$ and other substrates. ${ }^{28 b}$

The specificity of $\mathbf{8 c}$ for Cys should be useful in the determination of Cys in a background that may have structurally related compounds, such as biological samples also containing Hcy and other amino acids. Where probes specific for different compounds have distinct spectral ranges, they may be used together for determining different compounds simultaneously. For example, the 400-nm absorption of $\mathbf{8 c}$ does not overlap substantially with the 500-nm absorption for $\mathbf{6 a}$. Thus, $8 \mathbf{c}$ may be used in conjunction with $\mathbf{6 a}$ to detect Cys alone at $400 \mathrm{~nm}$ and total Cys plus Hcy at $500 \mathrm{~nm}$. The concentration of Hcy may then be inferred as $[\mathrm{Hcy}]=[\mathrm{Hcy}+\mathrm{Cys}]-[\mathrm{Cys}]$. We demonstrate a related approach in a new fluorescence assay for Hcy (vide infra).

\section{Site-Specific Peptide Labeling}

There is current interest in the site-specific labeling of peptides and proteins via either existing or engineered $\mathrm{N}$-terminal Cys residues. ${ }^{29}$ The fluorophores used include fluorescein or NIR dyes with appended thioester moieties. ${ }^{29}$ Pretreatment of peptides with $O$-methylhydroxylamine is needed to free the terminal Cys residues that may exist as thiazolidines due to reactions with carbonyl moieties of metabolites (thiazolidine formation is chemically reversible).$^{29}$ The thioester labeling reactions may require the use of additional reagents that can impact protein folding. ${ }^{29}$ The ligations typically require thiol cofactors such as thiophenol or benzylmercaptan. ${ }^{29}$ They are subject to thioester hydrolytic instability and side reactions. ${ }^{29} \mathrm{We}$ find that our aldehydeappended-dye techniques may find broader use in forming reversible and strong, covalent site-specific ( $N$-terminal cysteine) fluorescent labels. Solutions containing Cys-Gly exhibit spectrophotometric responses similar to those of Cys (Figure 3), while those containing Gly-Gly do not exhibit spectral changes (see Figure S5, Supporting Information). 


\section{Highly Selective Fluorescence Detection of Hcy Including Minimal Sample Pretreatment}

We do not observe significant fluorescence emission in the visible wavelength region from $\mathbf{8 c}$ and its Cys adduct(s) in buffer solution. We should thus be able to use $\mathbf{8 c}$ in a complex matrix to react with Cys to form relatively nonfluorescent products. In contrast, $\mathbf{6 a}$ exhibits high fluorescence emission in the visible region that quenches due to the presence of both Cys or Hcy (vide supra). We thus propose treating complex samples initially with $\mathbf{8 c}$ followed by $\mathbf{6 a}$. In this manner, $8 \mathbf{c}$ will react with Cys, leaving Hcy free to react with $\mathbf{6 a}$. Only fluorescence signaling due to Hcy should then be observed.

In deproteinized plasma spiked with (i) Cys or (ii) a combination of Cys and Hcy, and pretreated with $\mathbf{8 c}$, fluorescence quenching of $\mathbf{6 a}$ is due to Hcy concentration changes only (Figure 4). Thus, sample treatment with Cys-selective 8c, nonabsorbing at $470 \mathrm{~nm}$, is a simple way to enhance selective Hcy detection at another wavelength with other aldehydefunctionalized probes.

We show that this method can be used in relatively more complex native plasma solutions. Commercial lyophilized plasma is simply reconstituted in buffer ( $\mathrm{pH} 9.5)$. No deproteinization steps are performed. Hcy concentration-dependent emission changes are observed over a range of healthy $(6 \mu \mathrm{M})$ to dangerous levels $\left(1.3 \times 10^{-4} \mathrm{M}\right)$ levels, even in the presence of added excess Cys (Figure 5). Optimization of sensitivity is needed and is underway. We are studying near-infrared absorbing probes and other simple sample pretreatments.

\section{The Redox Chemistry of Biological Thiols and Selective Hcy Detection}

Biological thiols can be oxidized in nature to thiyl radicals via well-studied processes. ${ }^{30}$ The ensuing fate of these oxidizing radicals is of concern to public health. Two of the many characteristic reactions of thiyl radicals include the formation of a reducing disulfide radical anion (eq 1)

$$
\mathrm{RS}^{\bullet}+\mathrm{RS}^{-} \rightleftharpoons \mathrm{RSSR}^{\bullet-}
$$

and the formation of a reducing a-amino carbon-centered radical (eq 2).

$$
\mathrm{RS}^{\bullet} \rightleftharpoons{ }^{\bullet} \mathrm{CR}
$$

The analogous process in eq 2, which proceeds intermolecularly, is involved in "repairing" processes targeting the carbon-centered radicals of biomolecules. ${ }^{30}$

The formation of the a-amino alkyl radical of Cys was reported in 1971 by Neta. ${ }^{31}$ It was later described that the a-amino alkyl radical of GSH could be formed intramolecularly via the thiyl radical (as in eq 2). ${ }^{32,33}$ Zhao et al. reported in 1994 that intramolecular formation of captodatively stabilized a-amino alkyl radical in Hcy should be particularly favorable. ${ }^{33 a}$ This was attributed to an intramolecular hydrogen abstraction mechanism, which involves a favored 5-membered ring transition state (Scheme 3). ${ }^{33 a}$ Armstrong and co-workers have also made recent contributions concerning proton abstraction of thiyl radicals. They state that during biological repair processes, GSH thiyl radical can undergo either an inter- or an intramolecular process to form a carbon-centered radical with relatively equal ability. ${ }^{34}$

The dication methyl viologen (10) was used by Zhao et al. during thorough investigations of the equilibrium kinetics of the reducing disulfide (eq 1) and the reducing a-amino carboncentered radicals (eq 2) derived from the Hcy, Cys, and GSH thiyl radicals. ${ }^{33}$ The formation of reducing radicals was monitored via changes in the UV - vis absorbance 
spectra, indicating the production of the methyl viologen radical cation. ${ }^{33 a}$ Under the basic conditions used ( $\mathrm{pH}$ 10.5), no colorimetric selectivity among GSH, Cys, and Hcy was observed.

At neutral solution $\mathrm{pH}$, thiolate anion concentration is only a fraction of that of protonated thiol. Thus, at neutral $\mathrm{pH}$, reducing disulfide radical anion formation should be diminished (eq 1). The hydrogen atom (intramolecular proton-coupled electron) transfer process occurring via hydrogen atom abstraction, eq 2, which is most favored for Hcy (Scheme 3), should become more predominant at physiological $\mathrm{pH}$.

Additionally, zwitterionic amino acids cannot captodatively stabilize a-amino carboncentered radicals. When the ammonium moiety is deprotonated under alkaline conditions, rearrangement to captodatively stabilized carbon-centered radicals occurs much more readily and hence less selectively. We therefore reason that the formation of the reducing aamino alkyl radical should occur more readily in the case of Hcy compared to all other thiols, at neutral, rather than alkaline $\mathrm{pH}$.

Upon heating respective colorless solutions of $\mathbf{1 0}(8.0 \mathrm{mM}, \mathrm{pH} 7.5,0.5 \mathrm{M}$ Tris buffer $)$ containing specific biological thiols $(8.0 \mathrm{mM})$ at reflux for $5 \mathrm{~min}$, without protection from ambient air or light, visual signaling occurs selectively only for Hcy. The solution containing Hcy can be readily seen to turn blue, from colorless (Scheme 4). The color formation can be monitored via the appearance of absorptions at 398 and $605 \mathrm{~nm}$. Solutions of $\mathbf{1 0}$ containing Cys or GSH remain completely colorless upon heating. ${ }^{22 \mathrm{~b}}$

Common thiol determinations in plasma often require a deproteinization step after the reduction of disulfides to release the free thiols for analysis. Under our conditions, we find that deproteinization after reduction may not be necessary. Commercial plasma samples, spiked with Hcy, Cys, and GSH, upon heating in the presence of 10, afford selective blue color formation only corresponding to the presence of Hcy (Figure 6) under similar conditions as those described above. This result is completely consistent with our prior results in buffer solutions. ${ }^{22 \mathrm{~b}}$ It demonstrates that deproteinization procedures such as centrifugation may not be necessary in this determination technique, thereby potentially allowing for relatively facile sample pretreatment. Work on optimizing detection limit and sensitivity is continuing.

To extend the scope and generality of selective Hcy detection, we use electron-accepting fluorone black (11, Scheme 4), a commercially available xanthene dye, to confirm the Hcy selectivity observed with $\mathbf{1 0}$. Upon addition of 10 equiv of Hcy $\left(1.0 \times 10^{-4} \mathrm{M}\right.$ final concentration) to a solution of $\mathbf{1 1}\left(1.0 \times 10^{-5} \mathrm{M}\right)$ in $70 \% \mathrm{MeOH}: \mathrm{H}_{2} \mathrm{O}(\mathrm{MeOH}$ is used for solubility) at $\mathrm{pH} 7.3$, a change (increase) in absorbance at $510 \mathrm{~nm}$ is observed at room temperature. A similar, but relatively smaller, absorbance change is observed for Cys, GSH, and penicillamine (Figure 7). Other amino acids (glycine, alanine, serine, methionine, glutamine, lysine, arginine, threonine) and the disulfide homocystine do not promote a detectable absorbance change. ${ }^{22 b}$

The disulfide reduction in biological samples is often accomplished with a reducing agent such as a phosphine. We investigate the effect of $\mathrm{PPh}_{3}$ on this process, initially in order to mimic the conditions used to prepare biological samples for analysis via disulfide reduction. When $\mathrm{PPh}_{3}$ (45 equiv to dye 11) is present in the dye solution, an absorbance change only occurs in the presence of Hcy. No change is observed for Cys or other biological thiols. ${ }^{22 b}$ Concentration-dependent dye absorbance increases are thus observed only for Hcy. ${ }^{22 b}$ In addition, we observe selective fluorescence emission increases corresponding to the 
presence of Hcy under these conditions. No response is observed for Cys (see Figure S7, Supporting Information).

Interestingly, the UV - vis absorbance spectrum of a buffered solution of $\mathbf{1 1}$ with only added $\mathrm{PPh}_{3}$ exhibits absorbance increases in a similar fashion as it does when Hcy is added. This suggests that the phosphine may act as a competing reducing agent. We find that $\mathbf{1 1}$ enhances $\mathrm{O}=\mathrm{PPh}_{3}$ formation, in a solution of $\mathbf{1 1}$ and $\mathrm{PPh}_{3}$, as monitored via ${ }^{31} \mathrm{P}$ NMR spectroscopy. After $19 \mathrm{~h}, \mathrm{O}=\mathrm{PPh}_{3}$ formation is not observed in $\mathrm{PPh}_{3}$ solution that does not contain 11. In a $\mathrm{PPh}_{3}$ solution that contains $11, \mathrm{O}=\mathrm{PPh}_{3}$ formation is clearly observed. $\mathrm{O}=\mathrm{PPh}_{3}$ formation is well-known to proceed via the $\mathrm{PPh}_{3}$ radical cation. Thus, $\mathrm{PPh}_{3}$ inhibits the reduction of $\mathbf{1 1}$ with thiols other than Hcy by acting as a competing reducing agent.

Hcy can serve as the best reducing agent in the series $\mathbf{1 - 5}$. At least 45 equiv $\mathrm{PPh}_{3}$ (to dye) is needed to suppress the interactions of other thiols with $\mathbf{1 1}$. This is the threshold level of competing reducing $\mathrm{PPh}_{3}$ that allows for only Hcy-generated spectrophotometric changes in solutions of $\mathbf{1 1}-\mathrm{PPh}_{3}$. If a 30-fold molar excess of Cys (to Hcy) is added to a solution of Hcy $\left(1.0 \times 10^{-5} \mathrm{M}\right.$, approximating both Hcy and Cys levels in plasma), $\mathbf{1 1}\left(1.0 \times 10^{-5} \mathrm{M}\right)$, and $\mathrm{PPh}_{3}\left(1.5 \times 10^{-3} \mathrm{M}\right)$, no change in the spectrum compared to the original Hcy $\mathbf{- 1 1}$ solution is observed. ${ }^{22 \mathrm{~b}}$

We successfully use the standard addition method to determine Hcy in a commercial sample of human blood plasma. ${ }^{22 \mathrm{~b}}$ The calibration curve exhibits linearity in the working range from 0 to $15 \mu \mathrm{M}$. The percent recovery of Hcy is $102.9=7.3 \%$. The relative standard deviation (RSD) is $7.1 \%(n=3) .{ }^{22 b}$

Solutions of fluorescein, unlike 11, do not exhibit spectral changes in response to Cys or Hcy (Figure S10, Supporting Information). We thus propose that the formation of semiquinone radical in $\mathbf{1 1}$ is responsible for the signal changes observed (Scheme 4). Electron-transfer results in raising the $\mathrm{p} K_{\mathrm{a}}$ of the dye, as this corresponds to the absorbance increase of the dye at $510 \mathrm{~nm}$ that occurs upon addition of base.

\section{The Fate of the $\alpha$-Amino Carbon-Centered Radical of Hcy}

The study of metabolites of Hcy is of great importance (vide supra). Amino acid-derived free radicals are often implicated in DNA damage and the pathogenesis of disease. The readily formed Hcy alkyl radical might be a significant site of free radical damage initiation or propagation. We thus extend our prior work in the study of byproducts formed from the Hcy carbon-centered radical under ambient conditions (our fluorone black 11 assay). ${ }^{22 b}$ It has been reported that $a$-amino acid alkyl radicals form $\mathrm{NH}_{3}$ and several other radical termination and disproportionation products under ionizing radiation and relatively harsh oxidizing conditions. ${ }^{33,35}$

Several byproducts of Hcy alkyl radical reactions are identified under our assay conditions at room temperature by using MALDI-TOF MS (Table 2). Scheme 5 shows a proposed mechanism of formation of these products. Interestingly, compounds 13 and $\mathbf{1 8}$ have been found in the urine of patients with homocystinuria. ${ }^{36}$ It is possible that peroxide intermediate $\mathbf{1 2}$ could be the oxidant itself that plays a role along with $\mathbf{1 4}$ in the formation of disulfide $\mathbf{1 3}$. Thus, this study may provide a starting point as a chemical model for the reactions of the $a$ amino carbon-centered radical derived from Hcy in the human body under nonradiative conditions. 


\section{Effect of Transition Metals on the Detection of Hcy}

The oxidation of amino acids is generally catalyzed by transition metals. The mechanism of this process involves the formation of hydroxyl radicals (Fenton reaction). Therefore, studies of the oxidation of amino acids can be complicated by the presence of metal impurities in buffers and reagents. We thus investigate the effects of a chelating agent (EDTA) and an added transition metal $\left(\mathrm{Fe}^{3+}\right)$ under our conditions, for completeness.

EDTA is a commonly used metal-chelating agent in studies of metal-catalyzed amino acid oxidation reactions. In a study of Fenton chemistry, Stadtman et al. showed that the oxidation of amino acids could be either stimulated or inhibited by various metal chelating agents, depending on the actual ratios of chelating agents to iron salts. ${ }^{35}$ The varying amino acid oxidation or inhibition of oxidation corresponding to changes in the ratios of chelating agents to iron salts was attributed to variations in the composition, concentration, and redox potentials of the different complexes.

Upon addition of EDTA (20 equiv to 11) in our fluorone black assay, no differences in the UV - vis absorbance spectra are observed as compared to our standard techniques without EDTA (see Figure S8, Supporting Information). In addition, we find that no spectral changes occur upon addition of $\mathrm{FeCl}_{3}\left(1.0 \times 10^{-5} \mathrm{M}\right)$ under the same conditions (without EDTA; Supporting Information, Figure S9). The conclusion is that the mechanism shown in Scheme 3 best accounts for the observed Hcy selectivity in our assays, rather than Fenton chemistry.

\section{Automated Postcolumn HPLC Detection of Hcy in Human Plasma}

Recently, we have developed a simple HPLC post-column detection system for the analysis of mono- and oligosaccharides based on a boronic acid-derived chemosensor. ${ }^{37}$ Postcolumn detection allows for automation of the derivatization step and minimizes sample processing prior to analysis. Major concerns with introducing any new postcolumn techniques include (i) attaining appropriate reaction kinetics for generating an observable signal as well as (ii) diminishing background interference. Herein, we demonstrate the use of a library of aminothiol chemoselective reagents in a straightforward HPLC postcolumn detection format.

Figure 8 shows that using $\mathbf{1 0}$ as a postcolumn detection reagent results in the detection of Cys and Hcy ( $85 \mathrm{nmol}$ each) at $610 \mathrm{~nm}$. Figure 9a shows two sharp peaks corresponding to Cys and Hcy (28.8 nmol each) using 11 as a chromogenic reagent $(505 \mathrm{~nm})$. The same amount of six other selected amino acids (histidine, methionine, glutamine, lysine, glycine, and serine) was injected (Figure 9b,c) and no peaks were observed.

Figure 10a shows that two sharp peaks upon the co-injection of Cys and Hcy (43 nmol each) were observed with $\mathbf{6 a}$ as the postcolumn reagent. In addition, resolution is improved by switching the mobile phase to aqueous TFA (Figure 10b).

We also use compound 6a as a postcolumn reagent for the detection of Hcy in human plasma. We observe that the Hcy peak appears at $5.3 \mathrm{~min}$ (Figure 11b). The injection of twice the amount of unspiked plasma sample (Figure 11a) shows no interfering peak at 5.3 min. In addition, the Cys peak is wellresolved from that of Hcy, eluting at 3.6 min (Figure S11, Supporting Information). This primary screen of a small library of probes with aldehyde groups or electron-accepting properties shows the feasibility for the HPLC postcolumn detection of biological thiols. Such compounds may serve as alternatives to currently used electrophilic probes. 


\section{The Stability of Fluorescein Dialdehyde 6a}

Widely used monobromobimane is unstable in water and must be stored in solution at less than $-20^{\circ} \mathrm{C}$. The solutions must be replaced regularly. Batch-to-batch impurity levels vary significantly, presumably due to its instability (Table 1). Compound $6 \mathbf{a}\left(10^{-6} \mathrm{M}\right)$ in $0.1 \mathrm{M}$ carbonate buffer was stored for 2 weeks at room temperature in solution under ambient light. Minimal photobleaching is observed, only after 10 days (see Supporting Information, Figure S6).

The above HPLC studies demonstrate that (i) postcolumn reaction kinetics are fast enough for Hcy to be readily detected in all cases studied to date and (ii) the primary work with native plasma necessitates only simple sample pretreatment. It involves addition of TFA and rapid (seconds) syringe filtration (no centrifugation step). We obtain a chromatogram with a promising degree of resolution of the Hcy peak from plasma matrix peaks.

\section{Conclusion}

In conclusion, the unique ability of Hcy to form reducing carbon-centered radicals has led to the development of the first Hcy-selective probes, $\mathbf{1 0}$ and 11. The interaction of Cys with indicator $\mathbf{8 c}$ has afforded the most simple and selective Cys detection method reported to date. The indicators described herein can also be used in combination to achieve heightened selectivity for specific biothiols. They serve as highly chemo-selective alternatives to currently available thiol-reactive probes. Their use as HPLC detection reagents has thus far shown potential advantages. Currently, optimization and interlaboratory method validation are still ongoing.

The identification of several Hcy free-radical-derived intermediates and the mechanism of their formation as shown in Scheme 5 may help guide biomedical researchers in understanding the fate of Hcy under physiological conditions. For instance, rare metabolites such as $\mathbf{1 3}$, found in the urine of homocystinurics, were detected via the mild oxidation of Hcy at room temperature under our assay conditions. Our studies of the free radical chemistry of Hcy should complement the pioneering work by Jacobsen and co-workers, who previously demonstrated the unique ability of Hcy to selectively target biomolecules. ${ }^{\text {la }}$

Furthermore, studies by Jakubowski have shown that protein $N$-homocysteinylation (i.e., the amide-forming reaction of homocysteine thiolactone with lysine residues) may cause significant protein damage in humans. ${ }^{38}$ Thiazinane and free radical chemistry may aid the study of Hcy- $N$-proteins, since the 1,3-aminothiol moiety is free to promote reactions.

Our assays and associated NMR investigations demonstrate that Cys and Hcy can exhibit differing reactivities toward specific aldehyde-derived substrates. This may have implications in their respective roles in collagen disease, the inhibition of dopamine $\beta$ hydrolase, the inhibition of pyridoxal- $P$ enzymes, and other essential carbonyls. ${ }^{38}$ The results shown in Figure 3 demonstrate feasibility of effectively labeling or detecting $N$ terminal cysteine-containing biomolecules. The further study of the unique chemical reactivity of Cys, Hcy, and related compounds will be reported in due course.

\section{Experimental Section}

\section{General}

All chemicals were purchased from Sigma-Aldrich or Cambridge Isotope Labs and used without further purification. Lyophilized blood plasma was reconstituted with $\mathrm{H} 2 \mathrm{O}$. All spectroscopic data were acquired at room temperature. UV - vis data were obtained using a Spectramax Plus 384 spectrophotometer (Molecular Devices). Matrix-assisted laser 
desorption ionization mass spectra were acquired using a Bruker Proflex III MALDI mass spectrometer with and without matrix (anthracene or dithranol). Fluorescence spectra were recorded using a spectrofluorimeter SPEX Fluorolog-3 equipped with double excitation and emission monochromators and 400-W Xe lamp. NMR spectra were acquired on a Bruker DPX-250 or DPX-300 spectrometer. $1 \mathrm{H}$ and ${ }^{13} \mathrm{C}$ NMR spectra were obtained using $\mathrm{CD}_{3} \mathrm{OD}$, $\mathrm{D}_{2} \mathrm{O}$, DMSO- $d_{6} \cdot{ }^{31} \mathrm{P}$ NMR spectra were acquired in $70 \% \mathrm{CD}_{3} \mathrm{OD}, 30 \% \mathrm{D} 2 \mathrm{O}$, unless otherwise indicated. HPLC experiments were performed with a CM4000 multiple solvent delivery system (LDC/Milton Roy) and a SpectroMonitor $3100 \mathrm{UV}$ - vis detector (LDC/ Milton Roy) using a Lichrospher reverse-phase column $(4.6 \times 250 \mathrm{~mm}, 5 \mu \mathrm{m}$; Alltech Associates Inc.). The postcolumn detection system consisted of a He cylinder connected to a RDR-1 reagent delivery/reaction module (Timberline). The RDR-1 unit contains a pressurized reagent reservoir, a mixing tee, and a thermostated reaction block with a Teflon reaction coil ( 0.02 in. i.d. $\times 3 \mathrm{~m}$ ). The HPLC column was connected to the RDR-1. The RDR-1 was attached to a SpectroMonitor 3100 UV - vis detector (LDC/Milton Roy). The temperature of the reaction block was set to $80^{\circ} \mathrm{C}$. Absorbance was monitored at $510 \mathrm{~nm}$ for compound 6a, $610 \mathrm{~nm}$ for compound 10, and $505 \mathrm{~nm}$ for compound $\mathbf{1 1}$.

\section{Synthesis of Compounds $6 \mathrm{a}$ and $6 \mathrm{~b}$}

Fluorescein $(2.5 \mathrm{~g}, 7.75 \mathrm{mmol})$ and $3 \mathrm{~mL}$ of $\mathrm{MeOH}$ are placed in a $100 \mathrm{~mL}$ three-neck round-bottom flask. Next, $10 \mathrm{~g}$ of $50 \% \mathrm{NaOH}$ solution, $2.42 \mathrm{~mL}$ (30 mmol) of $\mathrm{CHCl}_{3}$, and $0.03 \mathrm{~mL}$ of 15 -crown- 5 are carefully added while the reaction temperature is maintained at $55^{\circ} \mathrm{C}$. The mixture is stirred at this temperature for $5 \mathrm{~h}$. After cooling, the mixture is acidified with $10 \mathrm{M} \mathrm{H}_{2} \mathrm{SO}_{4}$. The product precipitates. The solid is filtered and dried in vacuo overnight. Chromatography on silica gel (15:85 EtOAc:DCM) yields a white solid (6a) and a light yellow solid (6b). The yield for $\mathbf{6 a}$ is $92 \mathrm{mg}(3.1 \%)$ and for $\mathbf{6 b}$ is $952 \mathrm{mg}(34.1 \%)$. TLC: 6a $R_{f}=0.55$ (15:85 EtOAc:DCM), $6 \mathbf{b} R_{f}=0.28$ (15:85 EtOAc:DCM). Characterization data for 6 b. ${ }^{1} \mathrm{H}$ NMR (DMSO- $\left.d_{6}, 250 \mathrm{MHz}\right) \delta(\mathrm{ppm}): 6.60(2 \mathrm{H}, \mathrm{s}), 6.68$ $(1 \mathrm{H}, \mathrm{d}, J=8.9 \mathrm{~Hz}), 6.84(1 \mathrm{H}, \mathrm{s}), 6.92(1 \mathrm{H}, \mathrm{d}, J=8.9 \mathrm{~Hz}), 7.29(1 \mathrm{H}, \mathrm{d}, J=7.5 \mathrm{~Hz}), 7.69(1 \mathrm{H}$, $\mathrm{m}, J=1.1,7.5 \mathrm{~Hz}), 7.77(1 \mathrm{H}, \mathrm{m}, J=1.1,7.5 \mathrm{~Hz}), 7.99(1 \mathrm{H}, \mathrm{d}, J=7.5 \mathrm{~Hz}), 10.26(1 \mathrm{H}, \mathrm{S})$, $10.62(1 \mathrm{H}, \mathrm{s}), 11.87(1 \mathrm{H}, \mathrm{s}) .{ }^{13} \mathrm{C}$ NMR (DMSO- $\left.d_{6}, 300 \mathrm{MHz}\right) \delta(\mathrm{ppm}): 81.29,102.75$, 109.20,109.27, 109.75, 113.48, 113.63, 124.06, 124.89, 125.97, 129.07, 130.42, 135.91, 136.61, 150.94, 152.25, 152.46, 159.71, 163.04, 168.68, 192.94. FTIR (KBr, cm $\left.{ }^{-1}\right): 1007$, 1112, 1157, 1227, 1465, 1512, 1593, 1648, 1721, 3271. MALDI-TOF: $\mathrm{m} / z, 361.155$ [M + $\mathrm{H}]^{+}, 383.242[\mathrm{M}+\mathrm{Na}]^{+}$.

\section{Detection of Hcy in Deproteinized Plasma Samples}

Lyophilized commercial blood plasma samples are reconstituted in $0.1 \mathrm{M}$ carbonate buffer (pH 9.5) in one-third of the reconstitution volume. To the solution is added MeCN to attain the final reconstitution volume. The solution is exposed for $30 \mathrm{~min}$ at room temperature to precipitate proteins. The mixture is filtered through a $0.45 \mu \mathrm{m}$ HPLC filter after centrifugation at $5000 \mathrm{rpm}$. Cys is added to achieve a final concentration of $1.3 \times 10^{-4} \mathrm{M}$. Hcy is added in amounts up to $6.5 \times 10^{-4} \mathrm{M}$. Solutions of $\mathbf{8 c}$ in $\mathrm{MeOH}(0.2 \mathrm{~mL})$ are added to the plasma samples to a final concentration equal to that of Cys. Samples are stirred at room temperature for $20 \mathrm{~min}$. Next, a solution of $\mathbf{6 a}\left(1.7 \times 10^{-7} \mathrm{M}\right)$ in $0.1 \mathrm{M}$ carbonate

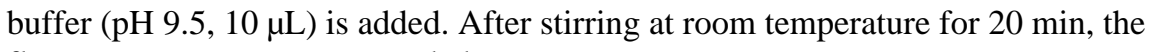
fluorescence spectra are recorded.

\section{Detection of Hcy in Native (Nondeproteinized) Plasma Samples}

Lyophilized commercial blood plasma samples are reconstituted in $0.1 \mathrm{M}$ carbonate buffer, $\mathrm{pH} 9.5$, as indicated on the label. Cys is added to achieve a final concentration of $1.3 \times 10^{-4}$ M. Hcy is added in amounts up to $1.3 \times 10^{-4} \mathrm{M}$. Solutions of $\mathbf{8 c}$ in $\mathrm{MeOH}(0.2 \mathrm{~mL})$ are 
added to the plasma samples to a final concentration equal to that of Cys. Samples are stirred at room temperature for $20 \mathrm{~min}$. Next, a solution of $6 \mathbf{a}\left(1.7 \times 10^{-7} \mathrm{M}\right)$ in $0.1 \mathrm{M}$ carbonate

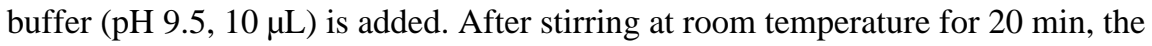
fluorescence spectra are recorded.

\section{Detection of Hcy in Human Blood Plasma Using 10}

Three $0.5-\mathrm{mL}$ aliquots of reconstituted human blood plasma are spiked with Hcy, Cys, and $\mathrm{GSH}(800 \mu \mathrm{M})$, respectively. Each spiked sample is mixed with $0.5 \mathrm{~mL}$ of a solution of $\mathbf{1 0}$ in Tris buffer ( $0.5 \mathrm{M}, \mathrm{pH} 7.5)$. The samples are refluxed on a hot plate until a blue color forms in the Hcy-containing solution (5 min).

\section{Effect of EDTA on the Detection of Hcy with 11}

A $0.2-\mathrm{mL}$ aliquot of a solution containing EDTA in $0.05 \mathrm{M}, \mathrm{pH} 7.3$ phosphate buffer (EDTA final concentration is $2.0 \times 10^{-4} \mathrm{M}$ ) is added to $0.1 \mathrm{~mL}$ of a solution of Hcy in the phosphate buffer (Hcy final concentration is $1.0 \times 10^{-4} \mathrm{M}$ ). The mixture is stirred for $5 \mathrm{~min}$. The UV - vis absorbance spectrum is acquired after the addition of a $0.7-\mathrm{mL} \mathrm{MeOH}$ solution containing $\mathbf{1 1}$ (final concentration of $\mathbf{1 1}$ is $1.0 \times 10^{-5} \mathrm{M}$ ) to the solution of EDTA and Hcy.

\section{Effect of $\mathrm{Fe}^{+}$on the Detection of Hcy with 11}

To a solution of Hcy $\left(1 \times 10^{-4} \mathrm{M}\right)$ in $0.05 \mathrm{M}$, pH 7.3 phosphate buffer $(0.3 \mathrm{~mL})$ is added 0.1 $\mathrm{mL}$ of a $\mathrm{MeOH}$ solution of $\mathrm{FeCl}_{3}\left(1.0 \times 10^{-5} \mathrm{M}\right)$. After addition of $0.6 \mathrm{~mL}$ of a $\mathrm{MeOH}$ solution of $11\left(1.0 \times 10^{-5} \mathrm{M}\right)$ to the solution containing $\mathrm{Hcy}$ and $\mathrm{FeCl}_{3}$, the $\mathrm{UV}$ - vis absorbance spectrum is acquired. All concentrations denoted above are final solution concentrations.

\section{Initial Evaluation of Fluorone Black (11) as a Postcolumn Reagent}

Conditions for chromatogram in Figure 9: mobile phase, 100\% of HPLC grade water; mobile phase flow rate, $1.5 \mathrm{~mL} / \mathrm{min}$; reagent, compound $11\left(1.25 \times 10^{-5} \mathrm{M}\right)$ in $50 / 50(\mathrm{v} / \mathrm{v})$ mixture of $\mathrm{MeOH}$ and aqueous carbonate buffer $(0.25 \mathrm{M}, \mathrm{pH} 9.5)$; reagent delivery pressure, $40 \mathrm{psi}$; reactor temperature, $80{ }^{\circ} \mathrm{C}$; detector wavelength, $505 \mathrm{~nm}$.

\section{Initial Evaluation of Methyl Viologen (10) as a Postcolumn Reagent}

Conditions for chromatogram in Figure 8: mobile phase, TFA $0.01 \mathrm{M}$; mobile phase flow rate, $1.5 \mathrm{~mL} / \mathrm{min}$; reagent, compound $10(0.01 \mathrm{M}$ in $0.25 \mathrm{M}$ carbonate buffer, $\mathrm{pH} 9.5)$; reactor temperature, $80^{\circ} \mathrm{C}$; detector wavelength, $610 \mathrm{~nm}$.

\section{Initial Evaluation of Fluorescein Dialdehyde (6a) as a Postcolumn Reagent}

Conditions (Figure 10a): mobile phase, $\mathrm{HPLC}$ grade $\mathrm{H}_{2} \mathrm{O}$; mobile phase flow rate, $1.5 \mathrm{~mL} /$ min; reagent, compound $6 \mathbf{6}\left(6.4 \times 10^{-6} \mathrm{M}\right.$ in carbonate buffer $\left.0.125 \mathrm{M}, \mathrm{pH} 9.5\right)$; reagent delivery pressure, $40 \mathrm{psi}$; reactor temperature, $80{ }^{\circ} \mathrm{C}$; detector wavelength, $510 \mathrm{~nm}$. Conditions (Figure 10b): mobile phase, $0.05 \%$ TFA; reagent delivery pressure, $60 \mathrm{psi}$; all the other conditions are the same as for Figure 10a.

\section{Compound 6a as Postcolumn Reagent for the Detection of Hcy in Human Plasma}

For the HPLC experiments described in Figure 11, the plasma was reconstituted with distilled water, treated with TFA, and filtered through an Alltech Polypure II $0.2 \mu \mathrm{m}$ filter. Conditions: mobile phase, $0.05 \%$ TFA; mobile phase flow rate, $1.0 \mathrm{~mL} / \mathrm{min}$; postcolumn reagent, compound $6 \mathbf{a}\left(3.2 \times 10^{-6} \mathrm{M}\right)$ in $0.125 \mathrm{M}$ carbonate buffer, $\mathrm{pH} 9.5$, and delivered applying $40 \mathrm{psi}$; reactor temperature, $80^{\circ} \mathrm{C}$; detector wavelength, $510 \mathrm{~nm}$. 


\section{Supplementary Material}

Refer to Web version on PubMed Central for supplementary material.

\section{Acknowledgments}

We thank the National Institutes of Health for funding this research via grant R01 EB002044. We also thank Dr. Donald Jacobsen of the Cleveland Clinic Foundation for helpful discussions.

\section{References}

1. a Carmel, R.; Jacobsen, DW. Homocysteine in Health and Disease. Cambridge, U.K: Cambridge University Press; 2001. b Lentz SR, Haynes WG. Cleveland Clin. J. Med. 2004; 71:730.

2. Seshadri S, Beiser A, Selhub J, Jacques PF, Rosenberg IH, D’Agostino RB, Wilson PWF. N. Engl. J. Med. 2002; 346:476. [PubMed: 11844848]

3. Steegerstheunissen RPM, Boers GHJ, Trijbels FJM, Eskes TKABN. N. Engl. J. Med. 1991; 324:199. [PubMed: 1984202]

4. Ueland PM, Vollset SE. Clin. Chem. 2004; 50:1293. [PubMed: 15277343]

5. Andus T, Mollers C, Geissler A, Vogl D, Gross V, Schmitz G, Hermann W, Scholmerich J. Gastroenterol. 1996; 110(Suppl. S):A855.

6. van Meurs JBJ, Dhonukshe-Rutten RAM, Pluijm SMF, van der Klift M, de Jonge R, Lindemans J, de Groot LCPGM, Hofman A, Witteman JCM, van Leeuwen JPTM, Breteler MMB, Lips P, Pols HAP, Uitterlinden AG. N. Engl. J. Med. 2004; 20:2033. [PubMed: 15141041]

7. Bienvenu T, Ankri A, Chadefaux B, Kamoun P. Presse Med. 1991; 20:985. [PubMed: 1829214]

8. a Klingman JG, Choi DW. Neurology. 1989; 39:397.b Janaky R, Varga V, Hermann A, Saransaari P, Oja SS. Neurochem. Res. 2000; 25:1397. [PubMed: 11059810]

9. Gazit V, Ben-Abraham R, Coleman R, Weizman A, Katz Y. Amino Acids. 2004; 26:163. [PubMed: 15042446]

10. Crawhall JC, Watts RWE. Am. J. Med. 1968; 45:736. [PubMed: 4879834]

11. Berlow S. Adv. Clin. Chem. 1967; 9:165. [PubMed: 5337431]

12. Shahrokhian S. Anal. Chem. 2001; 73:5972. [PubMed: 11791568]

13. Recent reviews: Nekrassova O, Lawrence NS, Compton RG. Talanta. 2003; 60:1085. [PubMed: 18969134] Refsum H, Smith AD, Ueland PM, Nexo E, Clarke R, McPartlin J, Johnston C, Engbaek F, Schneede J, McPartlin C, Scott JM. Clin. Chem. 2004; 50:3. [PubMed: 14709635]

14. a Ivanov AR, Nazimov IV, Baratova LA. J. Chromatogr. A. 2000; 870:433. [PubMed: 10722099] b Baeyens W, Van Der Weken G, Ling Ling B, De Moerloose P. Anal. Lett. 1988; 21:741.c Jacobsen DW, Gatautis VJ, Green R. Anal. Biochem. 1989; 178:208. [PubMed: 2729575] d Takahashi K. J. Biol. Chem. 1976; 80:1267.e Geoghegan KF, Hoth LR, Tan DH, Borzillerl KA, Withka JM, Boyd JG. J. Proteome Res. 2002; 1:181-187. [PubMed: 12643538] f Krokhin OV, Ens W, Standing KG. Rapid Commun. Mass Spectrom. 2003; 17:2528. [PubMed: 14608624] g Haugland, RP. Molecular Probes-Handbook of Fluorescent Probes and Research Products. 9th ed.. Eugene, OR: Molecular Probes, Inc.; 2002. p. 82h Svedas VJK, Galaev IJ, Borisov IL, Berezin IV. Anal. Biochem. 1979; 101:188. [PubMed: 7356128] i Fermo I, Arcellonic C, Mazzola G, D’angelo A, Paroni R. J. Chromatogr. B. 1998; 719:31.j Dai F, Burkert VP, Singh HN, Hinze WL. Microchem. J. 1997; 57:166.k Winters RA, Zukowski J, Ercal N, Matthews RH, Spitz DR. Anal. Biochem. 1995; 227:14. [PubMed: 7668373] 1 Al-Majed AA. Anal. Chim. Acta. 2000; 408:169.m Uchiyama S, Santa T, Okiyama N, Fukushima T, Imai K. Biomed. Chromatogr. 2001; 15:295. [PubMed: 11507712]

15. (a) Review: Ubbink JB. Semin. Thromb. Hemeostasis. 2000; 26:233. (b) see also ref 14 g, p 79.

16. Amarnath V, Amarnath K. Talanta. 2002; 56:745. [PubMed: 18968551]

17. a Chow C, Chiu BKW, Lam MHW, Wong W. J. Am. Chem. Soc. 2003; 125:7802. [PubMed: 12822989] b Chen S-J, Chang H-T. Anal. Chem. 2004; 76:3727. [PubMed: 15228347] c Ros-Lis JV, Garcia B, Jimenez D, Martinez-Manez R, Sanceron F, Soto J, Gonzalvo F, Valldecabres MC. J. Am. Chem. Soc. 2004; 126:4064. [PubMed: 15053569] d Li S-H, Yu C-W, Xu J-G. Chem. 
Commun. 2005:450.e Tanaka F, Mase N, Barbas CF III. Chem. Commun. 2004:1762.f Chow C-F, Lam MHW, Sui H, Wong W-Y. Dalton Trans. 2005:475. [PubMed: 15672191]

18. Refsum H, Ueland P, Svardal AM. Clin. Chem. 1989; 35:1921. [PubMed: 2776317]

19. Fiskerstrand T, Refsum H, Kvalheim G, Ueland P. Clin. Chem. 1993; 39:263. [PubMed: 8432015]

20. a Shipchandler MT, Moore EG. Clin. Chem. 1995; 41:991. [PubMed: 7600701] b Pernet P, Lasnier E, Vaubourdolle M. Clin. Chem. 2000; 46:1440. [PubMed: 10973885]

21. Ubbink JB, Delport R, Riezler R, Hayward-Vermaak W. J. Clin. Chem. 1999; 45:670.

22. a Rusin O, St. Luce NN, Agbaria RA, Escobedo JO, Jiang S, Warner IM, Strongin RM. J. Am. Chem. Soc. 2004; 126:438. [PubMed: 14719920] b Wang W, Escobedo JO, Lawrence CM, Strongin RM. J. Am. Chem. Soc. 2004; 126:3400. [PubMed: 15025448]

23. a Schubert MP. J. Biol. Chem. 1936; 114:341.b Schubert MP. J. Biol. Chem. 1937; 121:539.c Fourneau JP, Efimovsky O, Gaignault JC, Jacquier R, LeRidant C. R. Acad. Sci. Ser. C. 1971; 272:1517.

24. a Jencks WP. J. Am. Chem. Soc. 1959; 81:475.b Sayer JM, Peskin M, Jencks WP. J. Am. Chem. Soc. 1973; 95:4277.

25. Tam JP, Miao Z. J. Am. Chem. Soc. 1999; 121:9013. and references therein.

26. Burdette SC, Walkup GK, Spingler B, Tsien RY, Lippard SJ. J. Am. Chem. Soc. 2001; 123:7831. [PubMed: 11493056]

27. See Supporting Information.

28. (a) For 7-membered ring Cys-a, $\beta$-unsaturated aldehyde heterocyle adducts, see, for example: Starkenmann C. J. Agric. Food Chem. 2003; 51:7146. [PubMed: 14611186] (b) The L-serinederived Schiff base resonance appears at $\delta=8.01 \mathrm{ppm}$ and that of propylamine is observed at $\delta=$ 8.04 ppm, upon interaction with $\mathbf{8 c}$.

29. a Gentle IE, De Souza DP, Baca M. Bioconjugate Chem. 2004; 15:658.b Schuler B, Pannell LK. Bioconjugate Chem. 2002; 13:1039.

30. Brief overview: Abedinzadeh Z. Ca. J. Physiol. Pharmacol. 2001; 79:166.

31. Neta P, Fessenden RW. J. Phys. Chem. 1971; 75:2277.

32. a Sjöberg L, Eriksen TE, Revesz L. Radiat. Res. 1982; 89:255. [PubMed: 6278530] b Grierson L, Hildenbrand K, Bothe E. Int. J. Radiat. Biol. 1992; 62:265. [PubMed: 1356129]

33. Zhao R, Lind J, Merényi G, Eriksen TE. J. Am. Chem. Soc. 1994; 116:12010. Zhao R, Lind J, Merényi G, Eriksen TE. J. Chem. Soc. Perkins Trans. 1997; 2:569. and references therein.

34. For example, Rauk A, Armstrong DA, Fairlie DP. J. Am. Chem. Soc. 2000; 122:9761. and references therein.

35. Stadtman ER. Annu. Rev. Biochem. 1993; 62:797. [PubMed: 8352601]

36. Review: Cooper AL. Annu. Rev. Biochem. 1983; 52:187. [PubMed: 6351723]

37. Kim KK, Escobedo JO, St. Luce NN, Rusin O, Wong D, Strongin RM. Org. Lett. 2003; 5:5007. [PubMed: 14682751]

38. A recent review: Jakubowski H. Cell. Mol. Life Sci. 2004; 61:470. [PubMed: 14999406] 
<smiles>N[C@@H](CCS)C(=O)O</smiles>

$\underset{1}{\text { homocysteine }}$

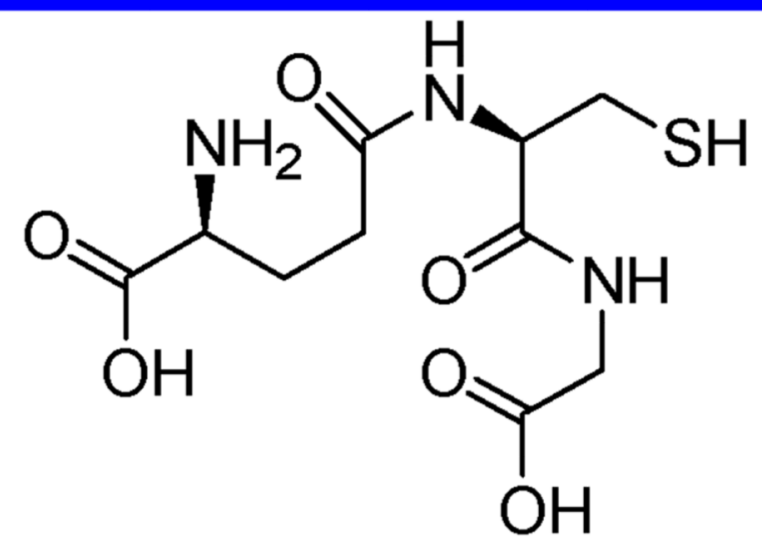

glutathione

2<smiles>NC(CS)C(=O)O</smiles>

cysteine

3<smiles>CC(=O)N[C@@H](CS)C(=O)O</smiles>

$N$-acetylcysteine

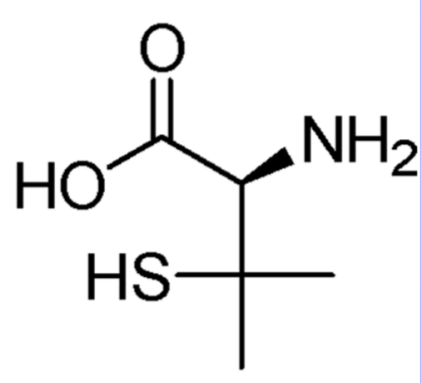

penicillamine

Figure 1.

Structures of selected bioactive thiols. 


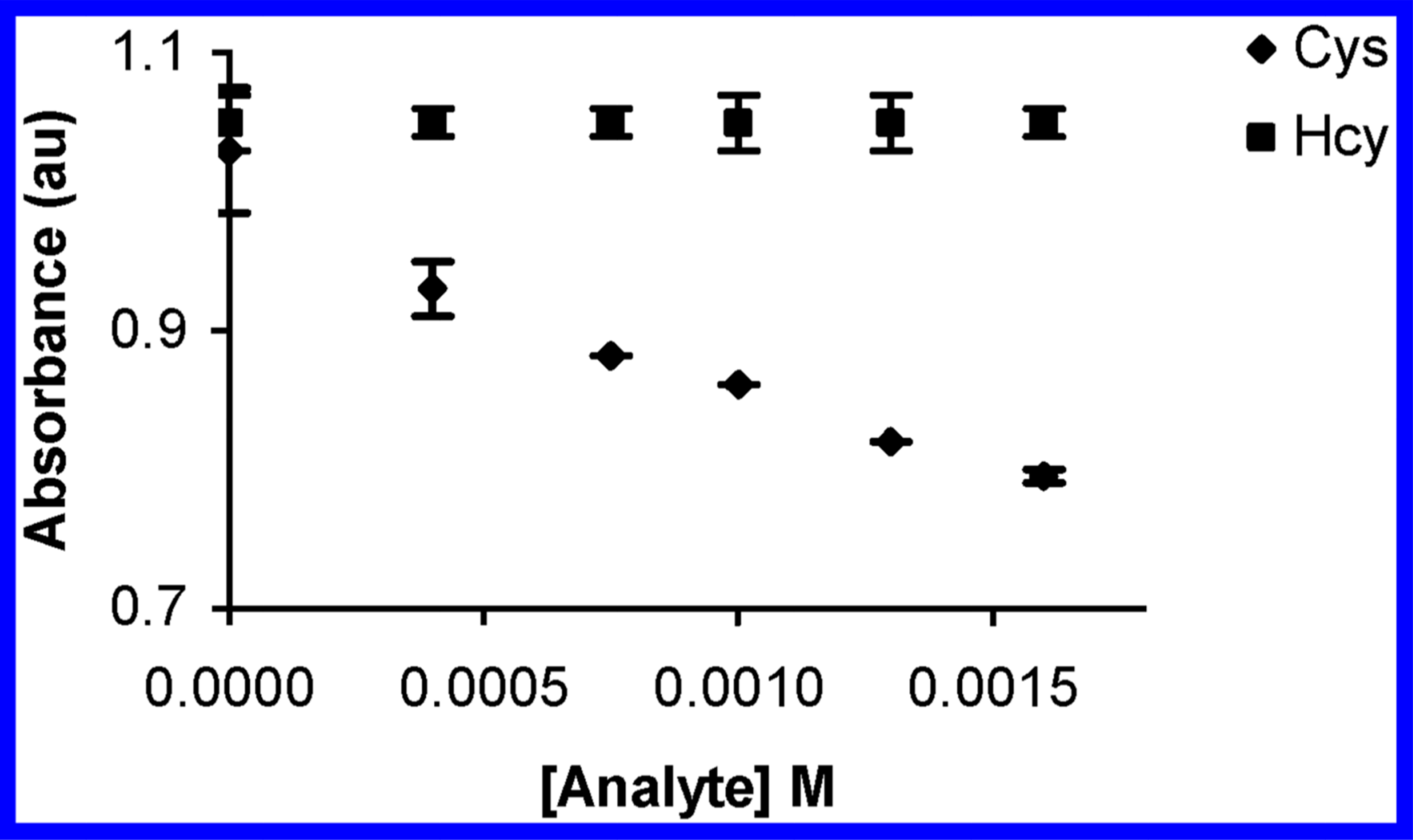

Figure 2.

Absorbance at $400 \mathrm{~nm}$ of solutions of $\mathbf{8 c}$ with added Cys or Hcy. Only a change in signaling due to Cys is observed. 


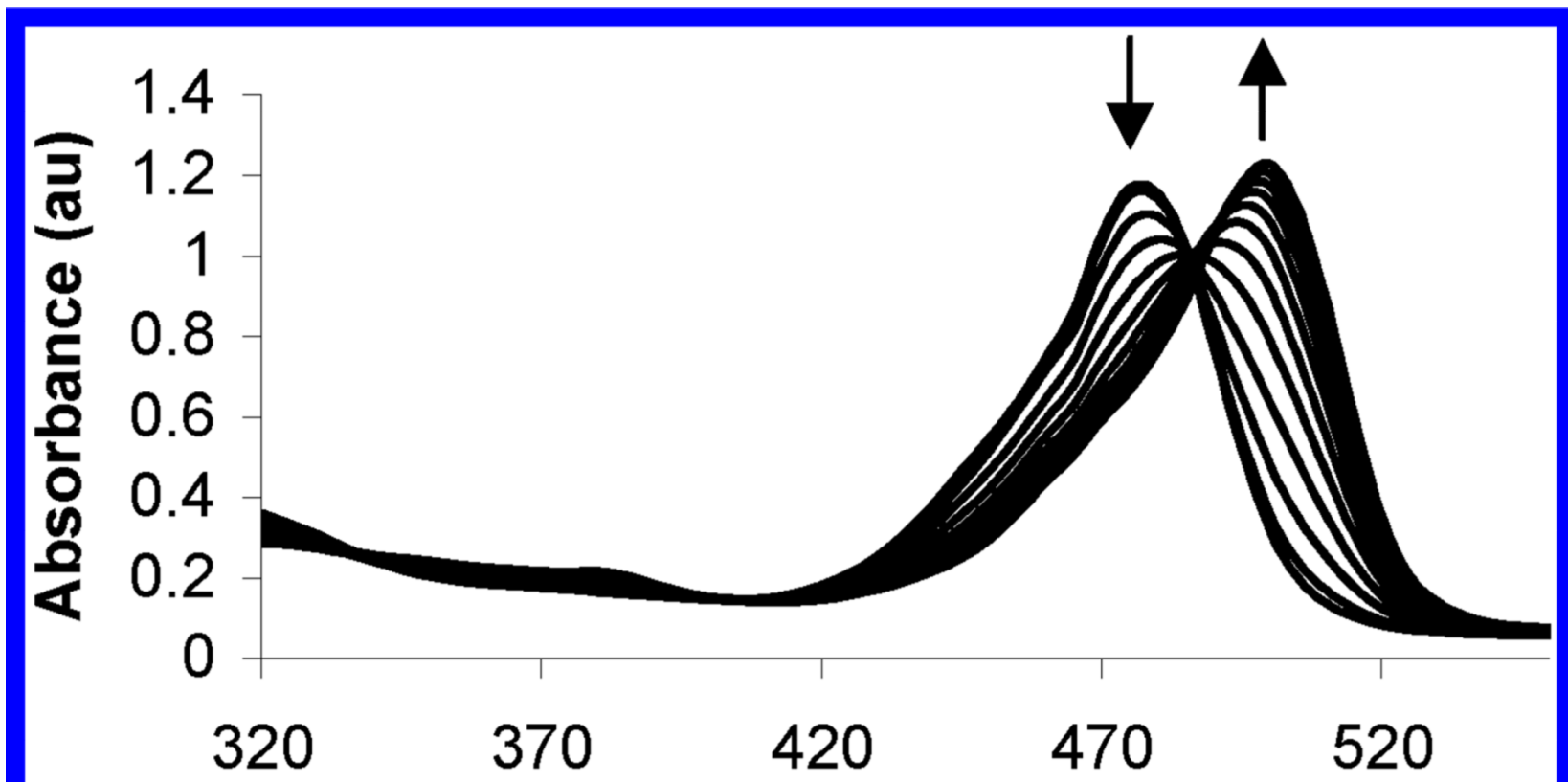

Wavelength (nm)

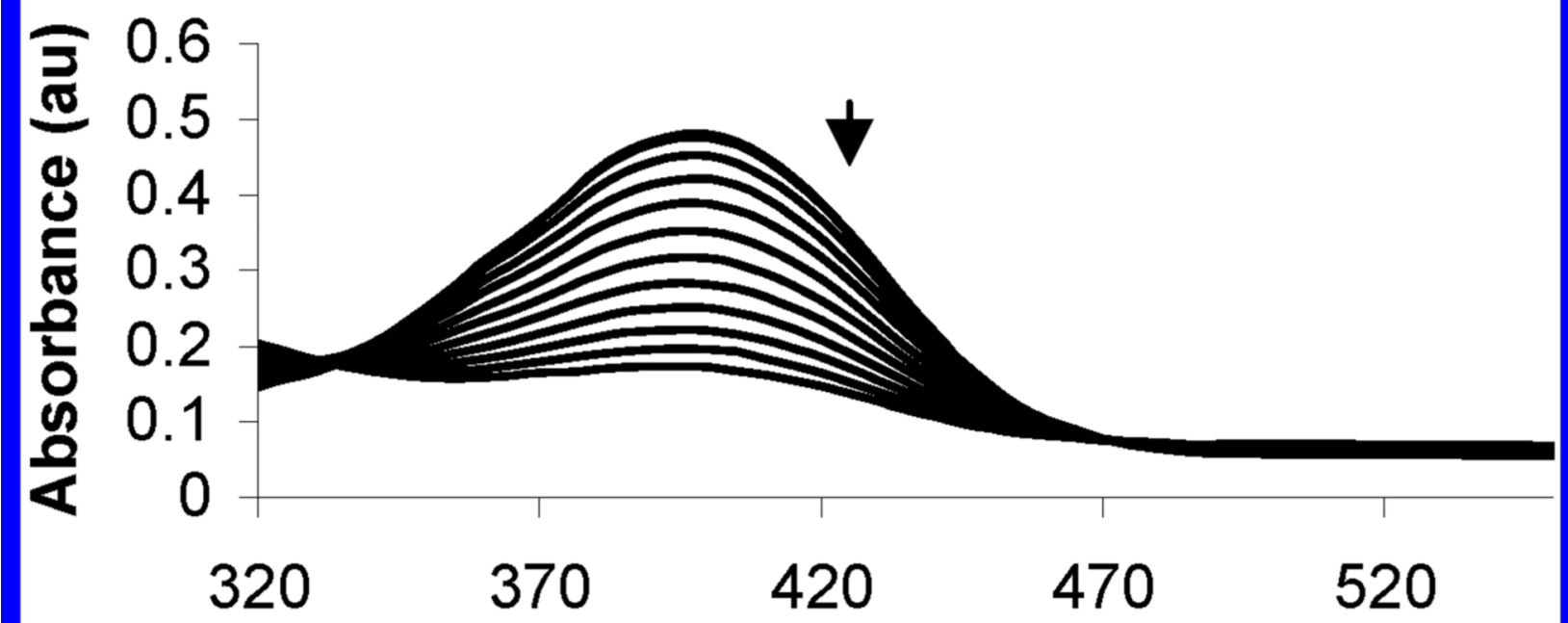

Wavelength (nm)

Figure 3.

Top: UV - vis absorbance spectra of $6 \mathbf{a}\left(3 \times 10^{-6} \mathrm{M}\right)$ with varying concentrations of CysGly $\left[\left(4 \times 10^{-6}\right)-\left(8 \times 10^{-5} \mathrm{M}\right)\right]$ in $0.1 \mathrm{M}$ carbonate buffer, $\mathrm{pH} 9.5$, at room temperature. Bottom: UV - vis absorbance spectra of $8 \mathbf{c}\left(3 \times 10^{-6} \mathrm{M}\right)$ with varying concentrations of Cys-Gly $\left[\left(4 \times 10^{-6}\right)-\left(8 \times 10^{-5} \mathrm{M}\right)\right]$ in $0.1 \mathrm{M}$ carbonate buffer, $\mathrm{pH} 9.5$, at room temperature. Spectrophotometric changes are insignificant for control dipeptide Gly-Gly (see Supporting Information). 

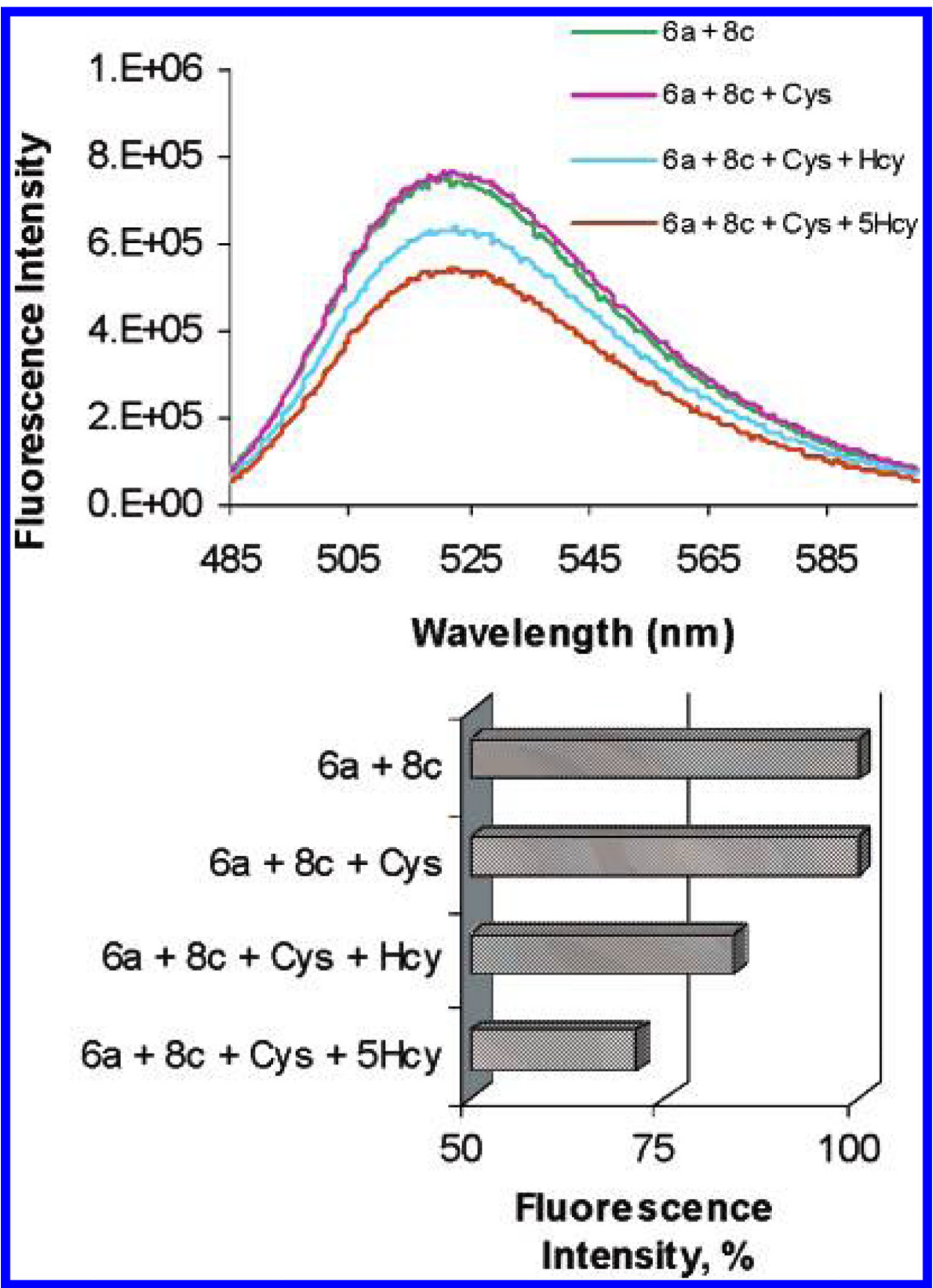

Figure 4.

Fluorescence emission spectra of deproteinized plasma solutions; excitation is at $470 \mathrm{~nm}$, pH 9.5, room temperature. $6 a\left(1.7 \times 10^{-7} \mathrm{M}\right)$ and $8 \mathbf{c}\left(1.3 \times 10^{-4} \mathrm{M}\right)$ are present. Cys $(1.3 \times$ $\left.10^{-4} \mathrm{M}\right)$ is added to all solutions. There is no change in fluorescence emission due to added Cys. When 1 equiv of Hcy $\left(1.3 \times 10^{-4}\right)$ is added, there is a change in fluorescence emission. Addition of 4 equiv more of Hcy produces a further quenching of fluorescence at $525 \mathrm{~nm}$. 


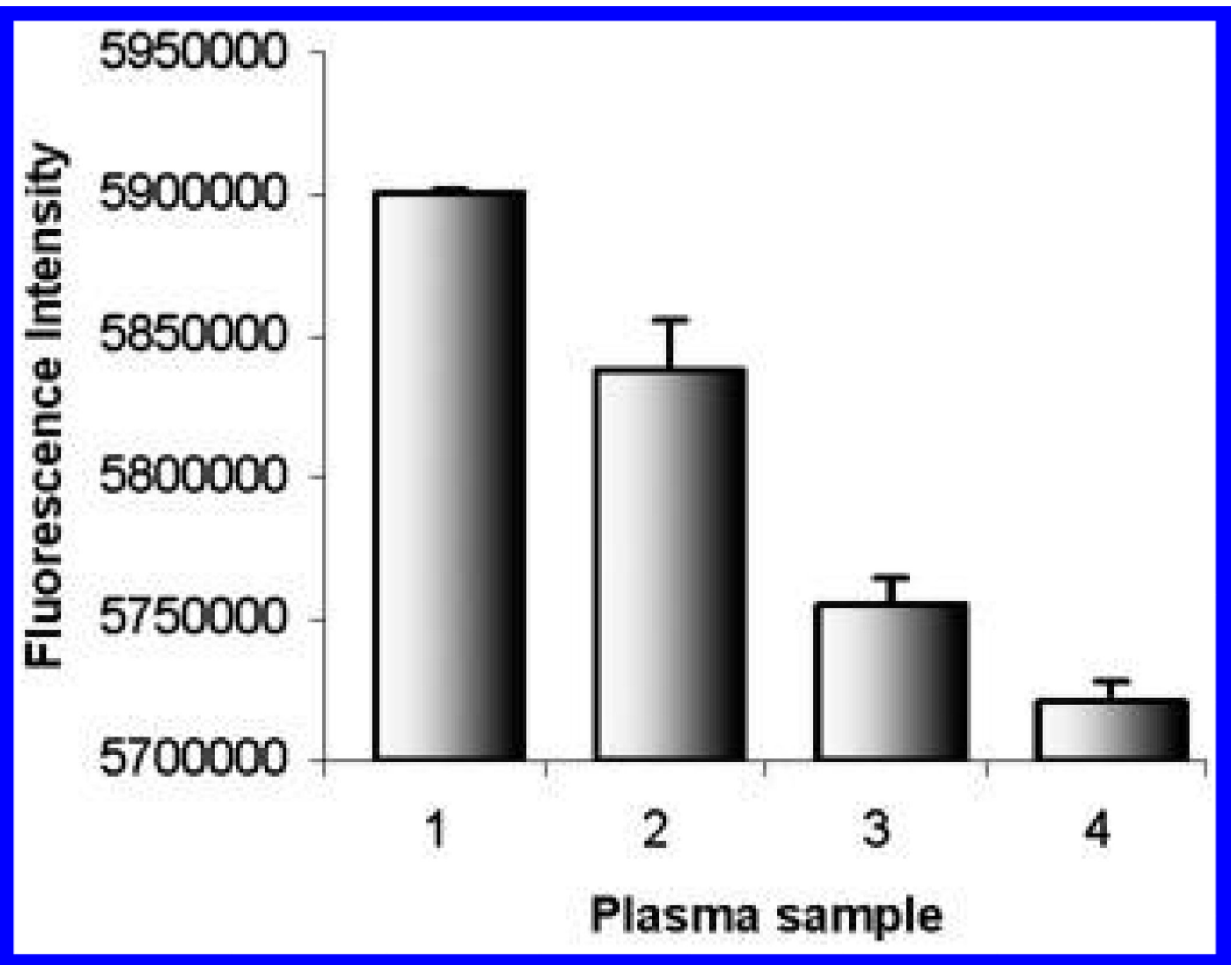

Figure 5.

Fluorescence emission intensity at $525 \mathrm{~nm}$ of solutions of $\mathbf{6 a}\left(2 \times 10^{-5} \mathrm{M}\right), \mathbf{8 c}\left(2 \times 10^{-3} \mathrm{M}\right)$, and blood plasma containing added Cys $\left(2 \times 10^{-3} \mathrm{M}\right)$. The concentration of Hcy is varied in the plasma samples as follows: sample $1=0 \mathrm{M}$, sample $2=6 \times 10^{-6} \mathrm{M}$, sample $3=1.3 \times$ $10^{-5} \mathrm{M}$, sample $4=1.3 \times 10^{-4} \mathrm{M}$. As the concentration of Hcy increases, quenching of fluorescence emission is observed. The error bars are based on three runs. The highest error value (sample 2) accounts for $1.2 \times 10^{-6} \mathrm{M}$ Hcy. These promising results are currently being optimized. 


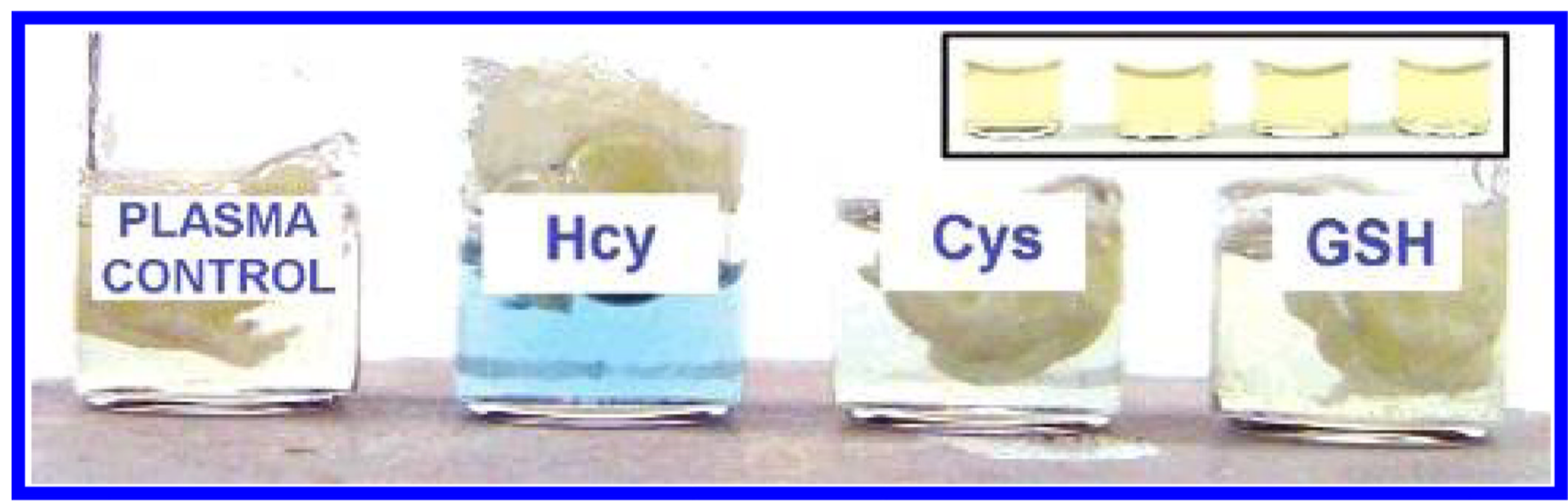

Figure 6.

Selective Hcy detection in human plasma without prior deproteinization. Only the Hcyspiked sample turns blue (added thiol left to right: none, Hcy, Cys, GSH, 4.0 mM final thiol concentration). Inset: samples before heating. 


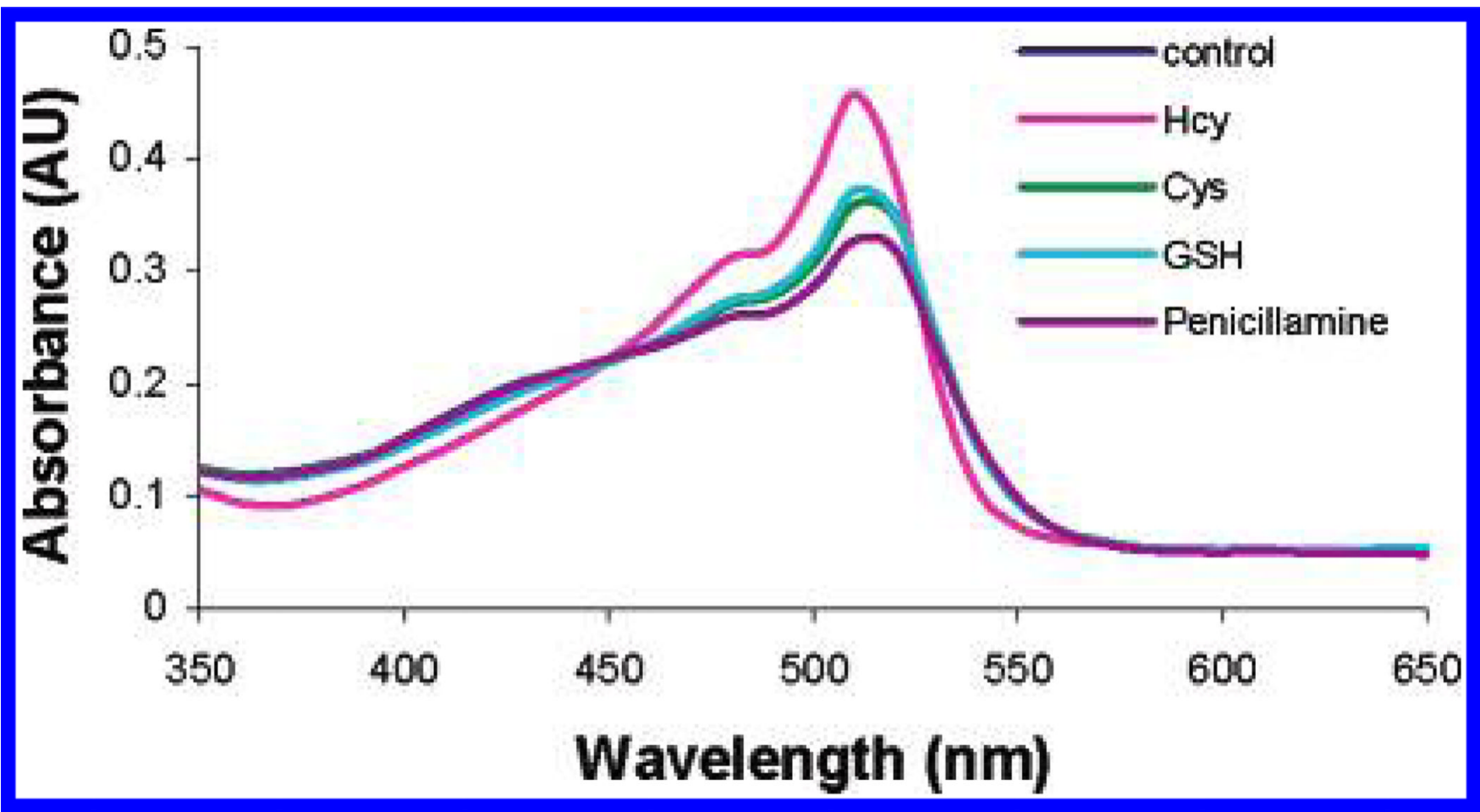

Figure 7.

UV - vis absorbance spectra of solutions containing $11\left(1.0 \times 10^{-5} \mathrm{M}\right)$ and different biological thiols $\left(1.0 \times 10^{-4} \mathrm{M}\right)$. 


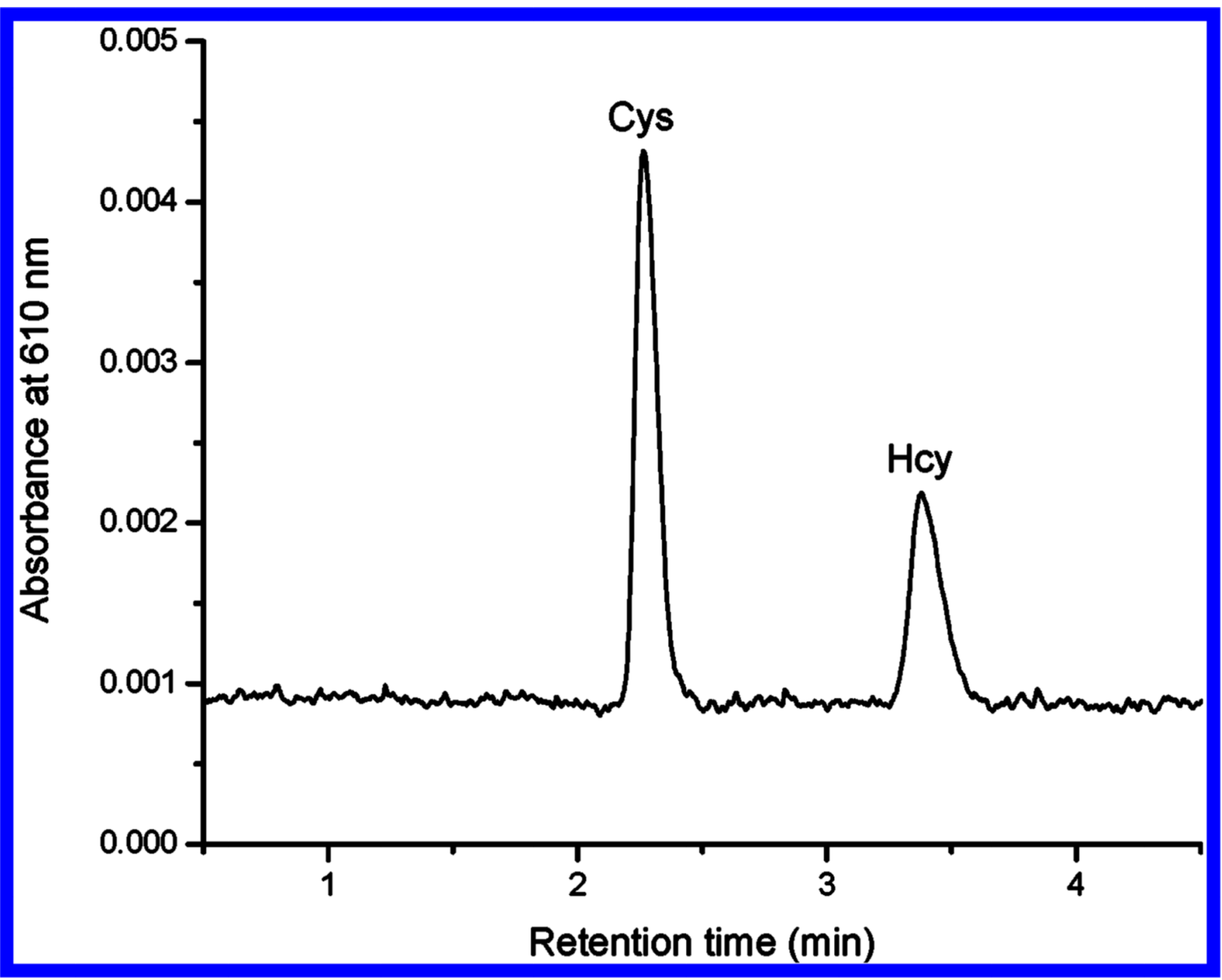

Figure 8.

Chromatogram of a mixture of Cys and Hcy using compound $\mathbf{1 0}$ as postcolumn reagent. 


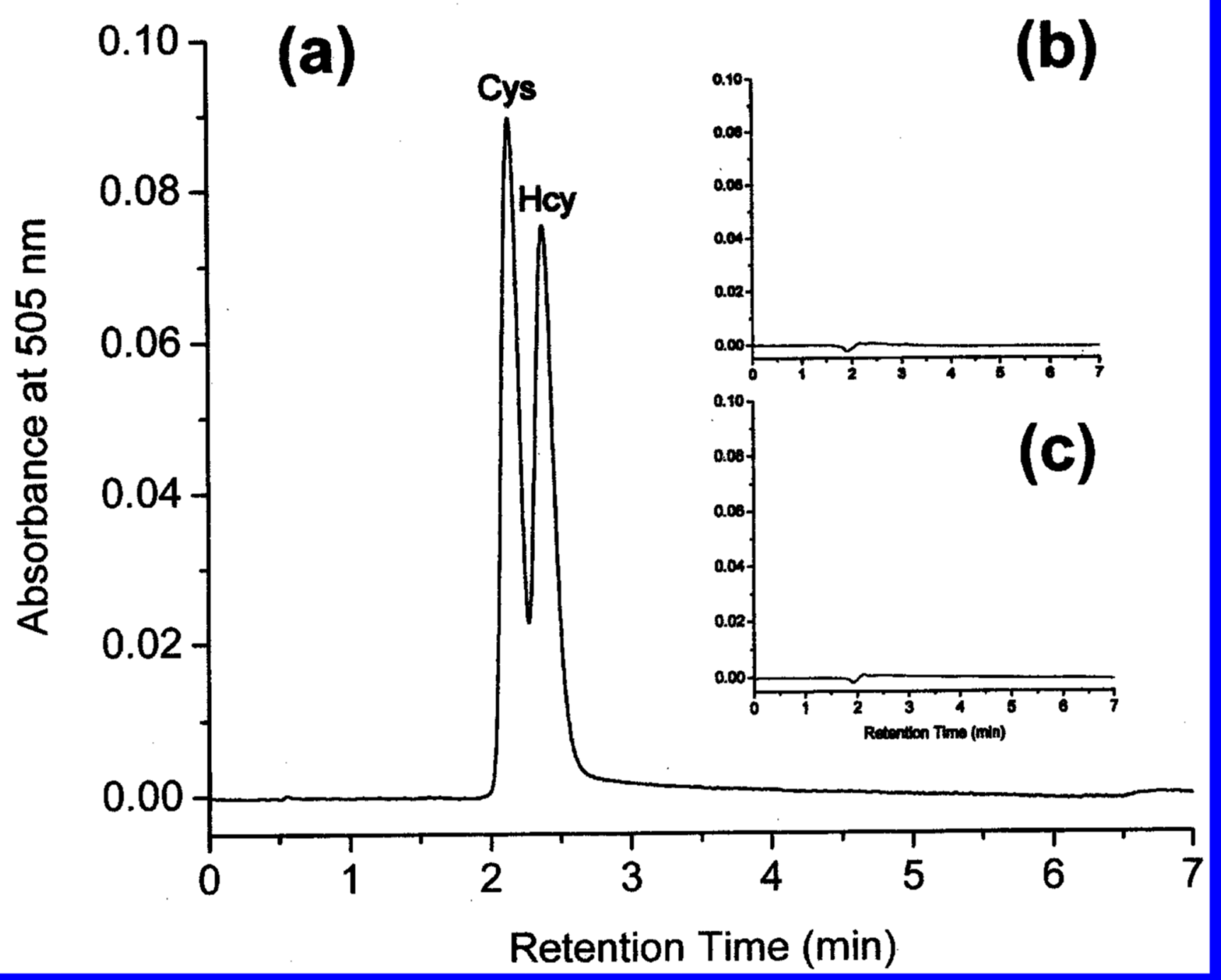

Figure 9.

Chromatograms of mixtures of (a) Cys and Hcy; (b) histidine, methionine, and glutamine; and (c) lysine, glycine, and serine using $\mathbf{1 1}$ as the postcolumn reagent. 

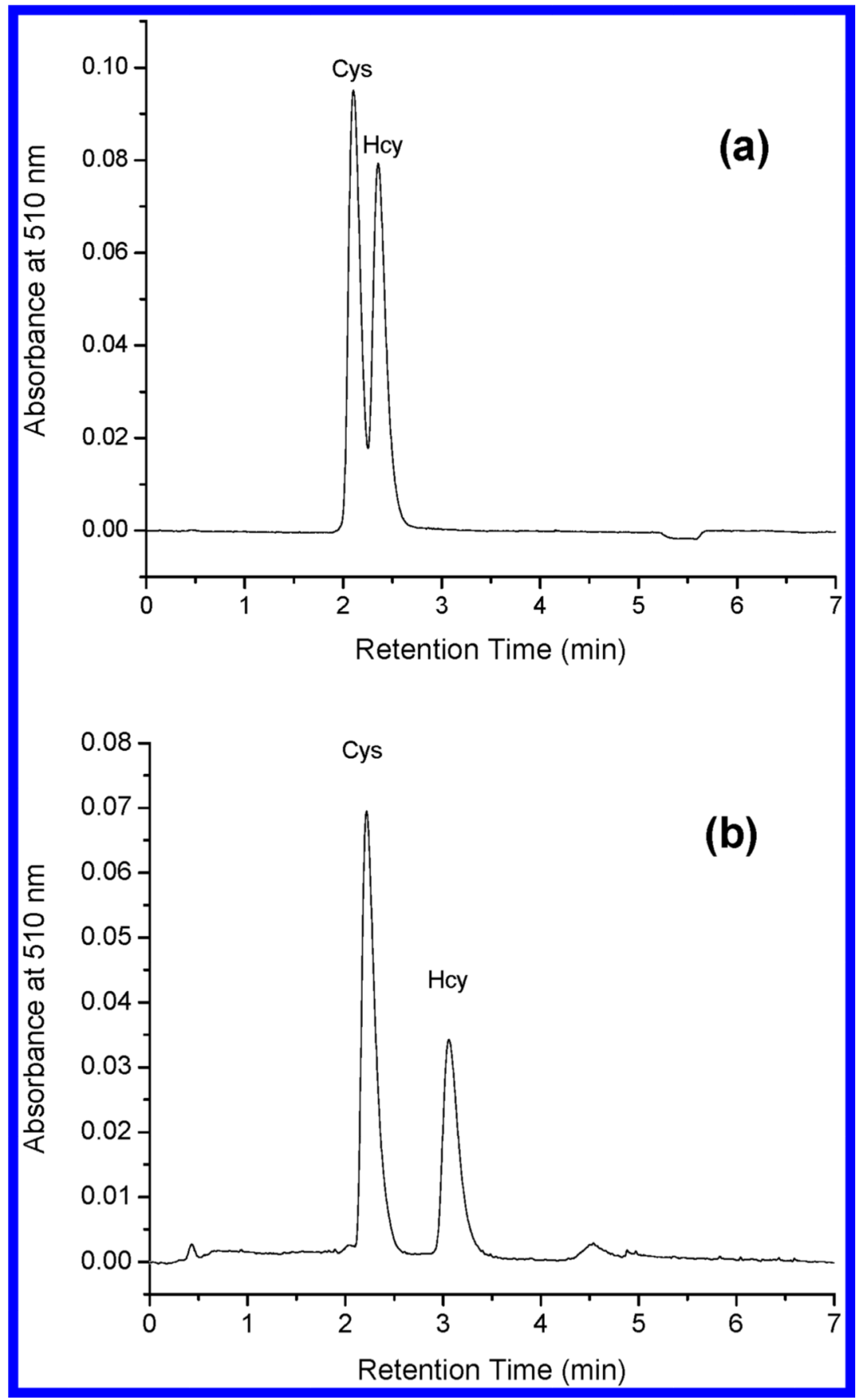

Figure 10.

Chromatograms of mixtures of Cys and Hcy using $6 \mathbf{a}$ as postcolumn reagent. (a) separation using HPLC grade water as mobile phase; (b) separation using $0.05 \%$ TFA solution to improve resolution. 

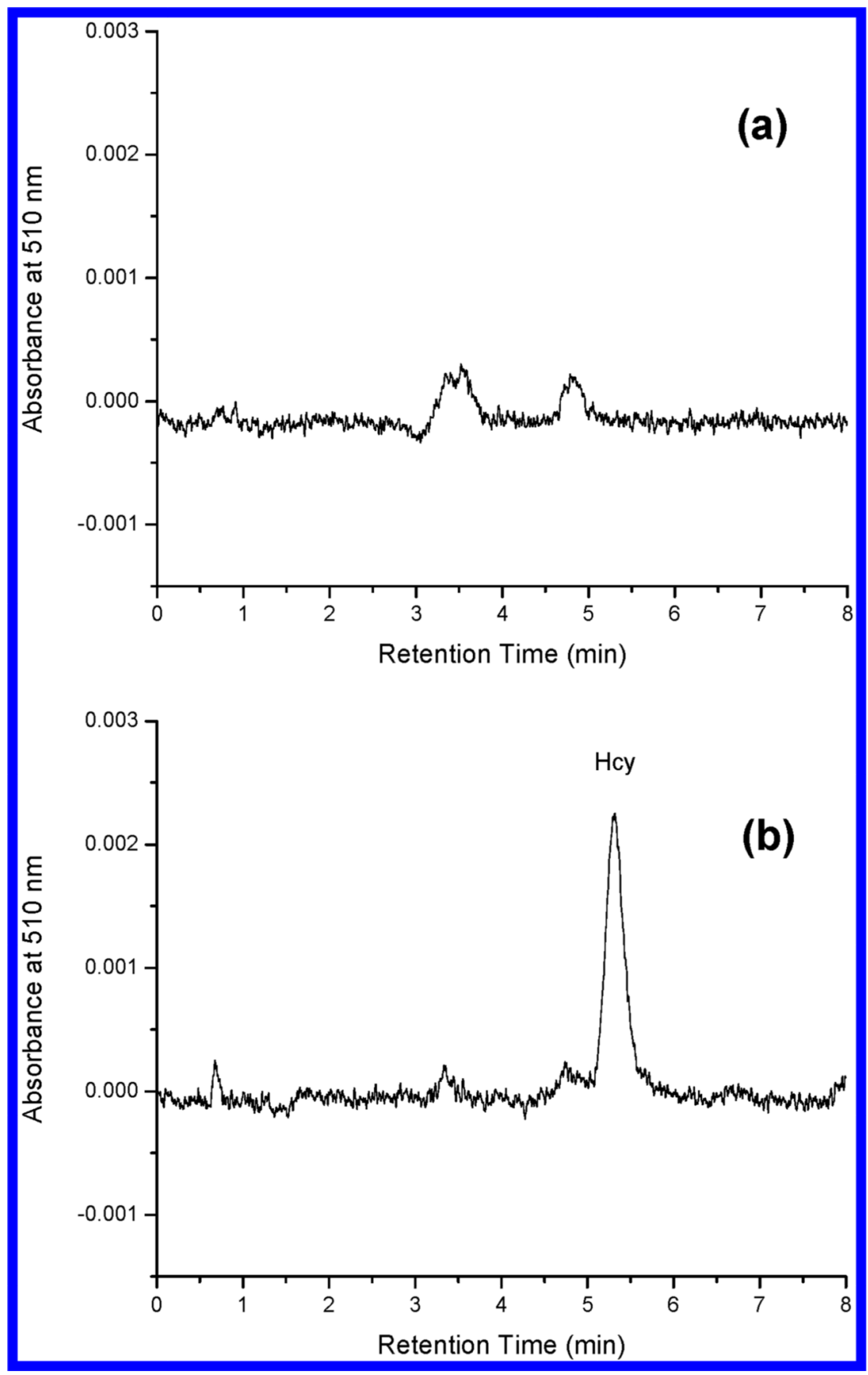

Figure 11.

(a) Chromatogram of a sample of human plasma using $\mathbf{6 a}$ as the postcolumn reagent. Lyophylized plasma is reconstituted with deionized water $(1 \mathrm{~mL})$. The solution is mixed with $100 \mu \mathrm{L}$ of TFA and syringe-filtered. It is diluted five times with water before injection. (b) Chromatogram of a sample of human plasma spiked with Hcy using $\mathbf{6 a}$ as postcolumn reagent. The reconstituted plasma mixed with $100 \mu \mathrm{L}$ of TFA was diluted 10 times with water and spiked with Hcy (9.5 nmol of Hcy injected). 


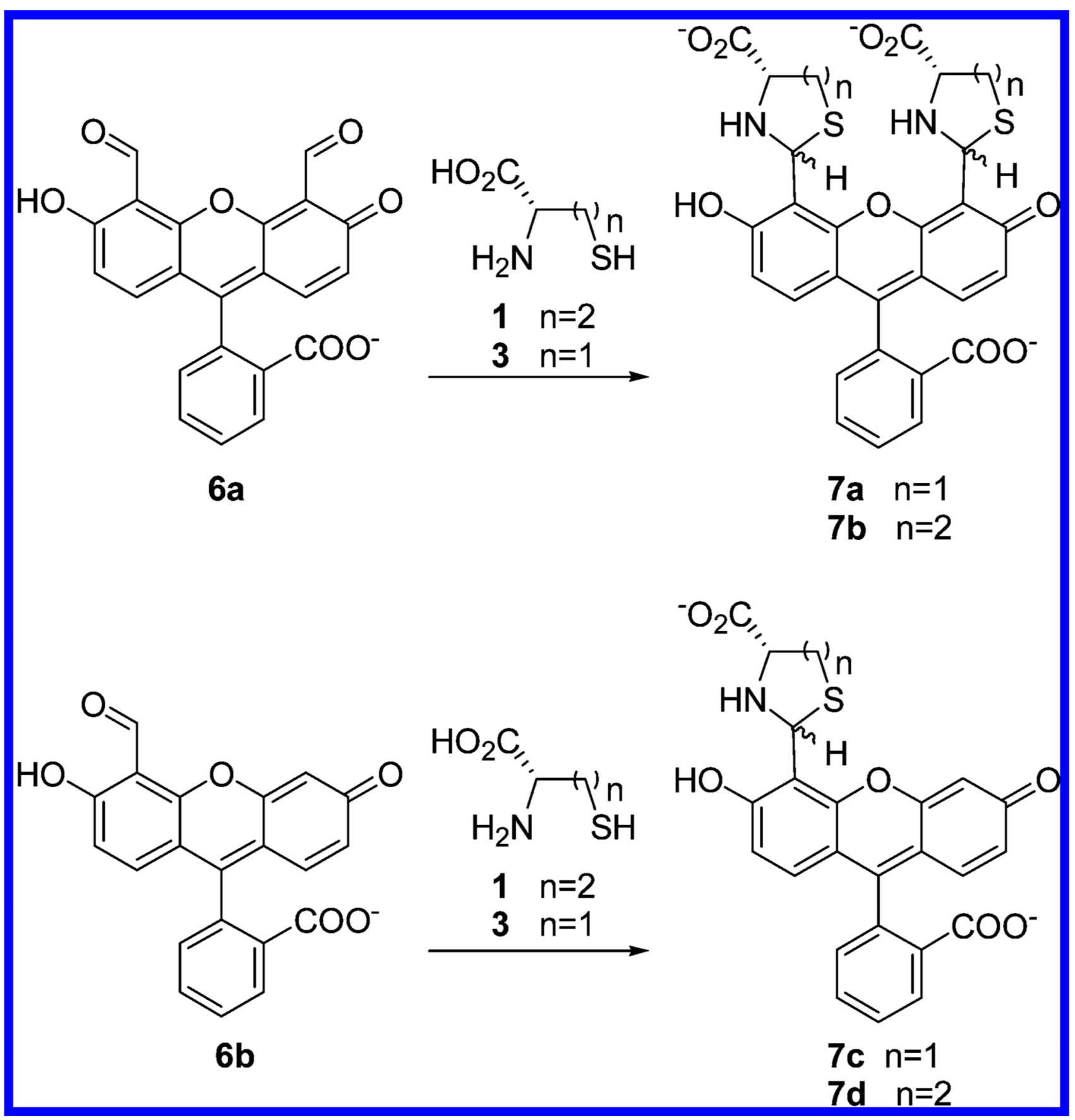

Scheme 1.

Formation of Cys-Derived Thiazolidines and Hcy-Derived Thiazinanes from Fluorescein Dialdehyde $6 \mathbf{a}$ and Monoaldehyde $\mathbf{6 b}$ 


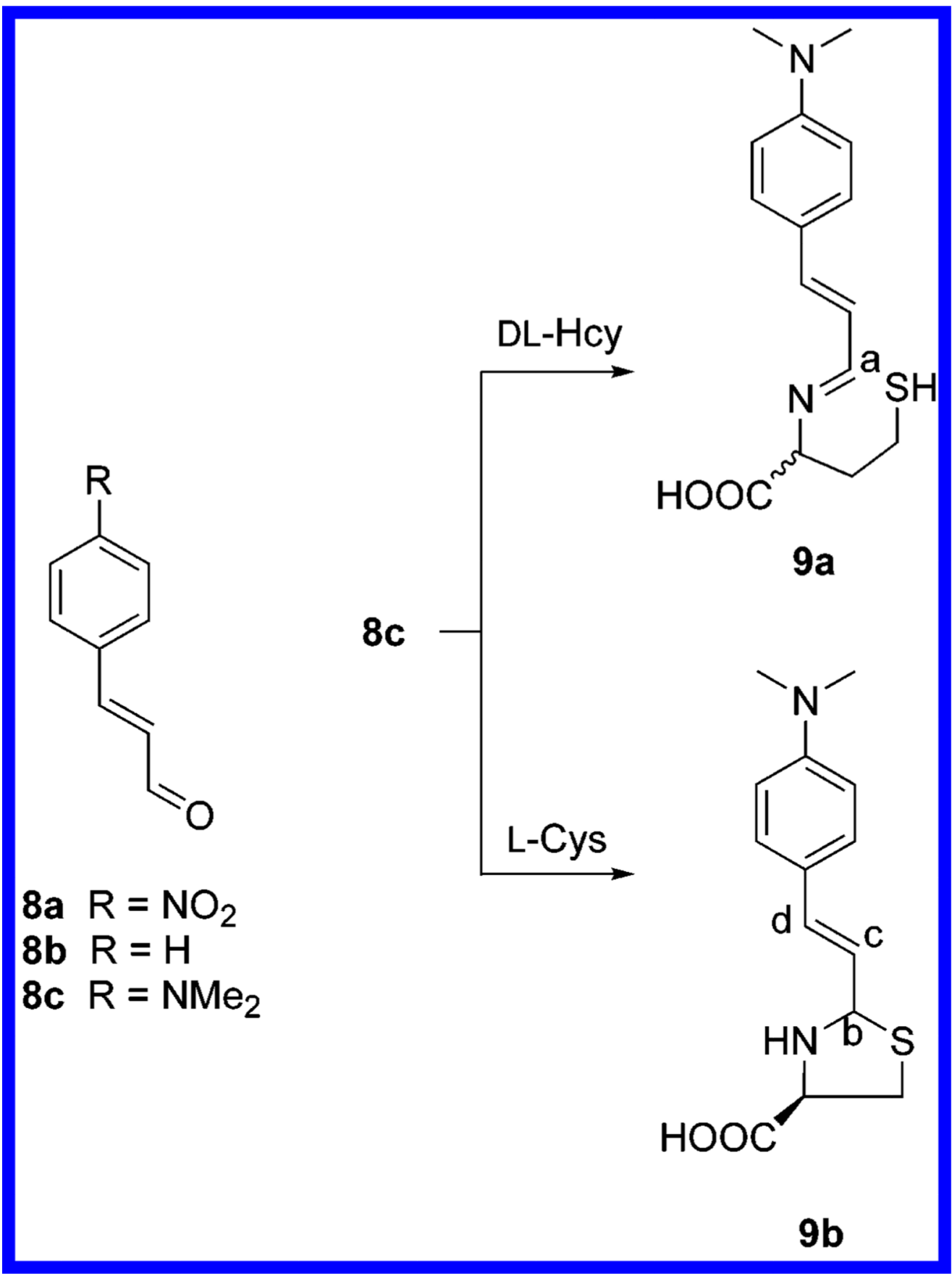

Scheme 2.

Products 9a and 9b Have Been Identified in the Reaction of Hcy or Cys, Respectively, with 8c 


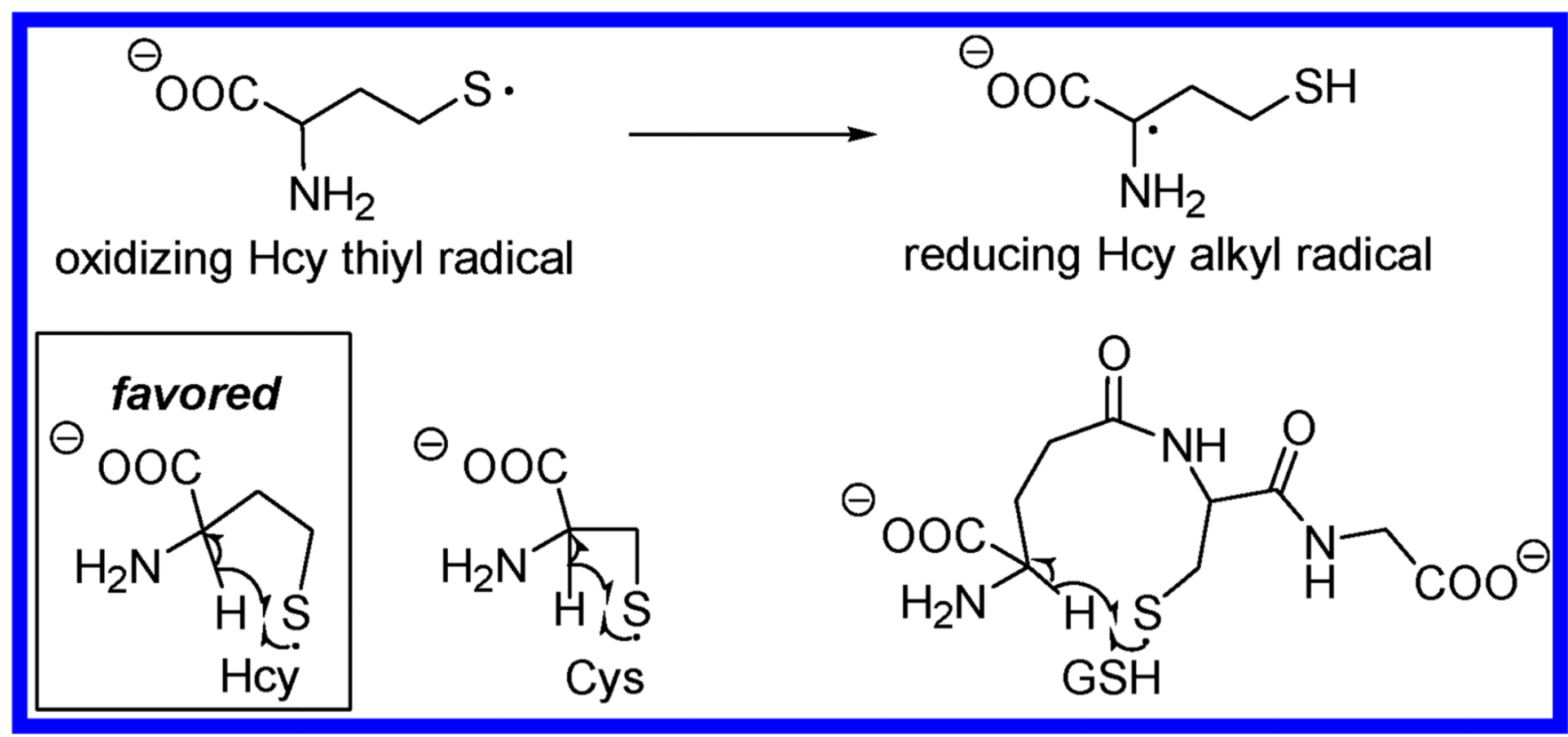

Scheme 3. 


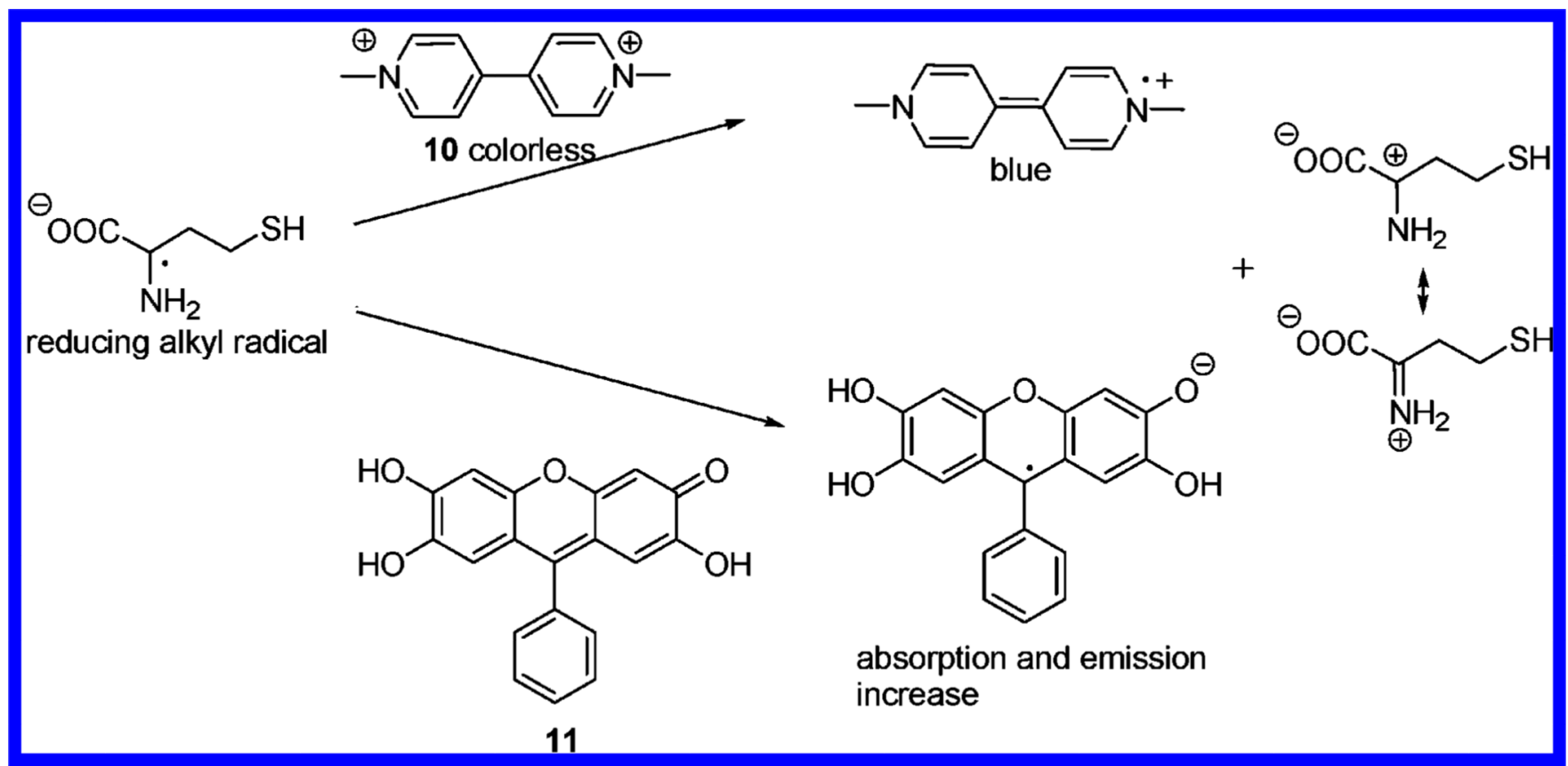

Scheme 4.

Electron Transfer from the Hcy Carbon-Centered Radical to Methyl Viologen or Fluorone Black 


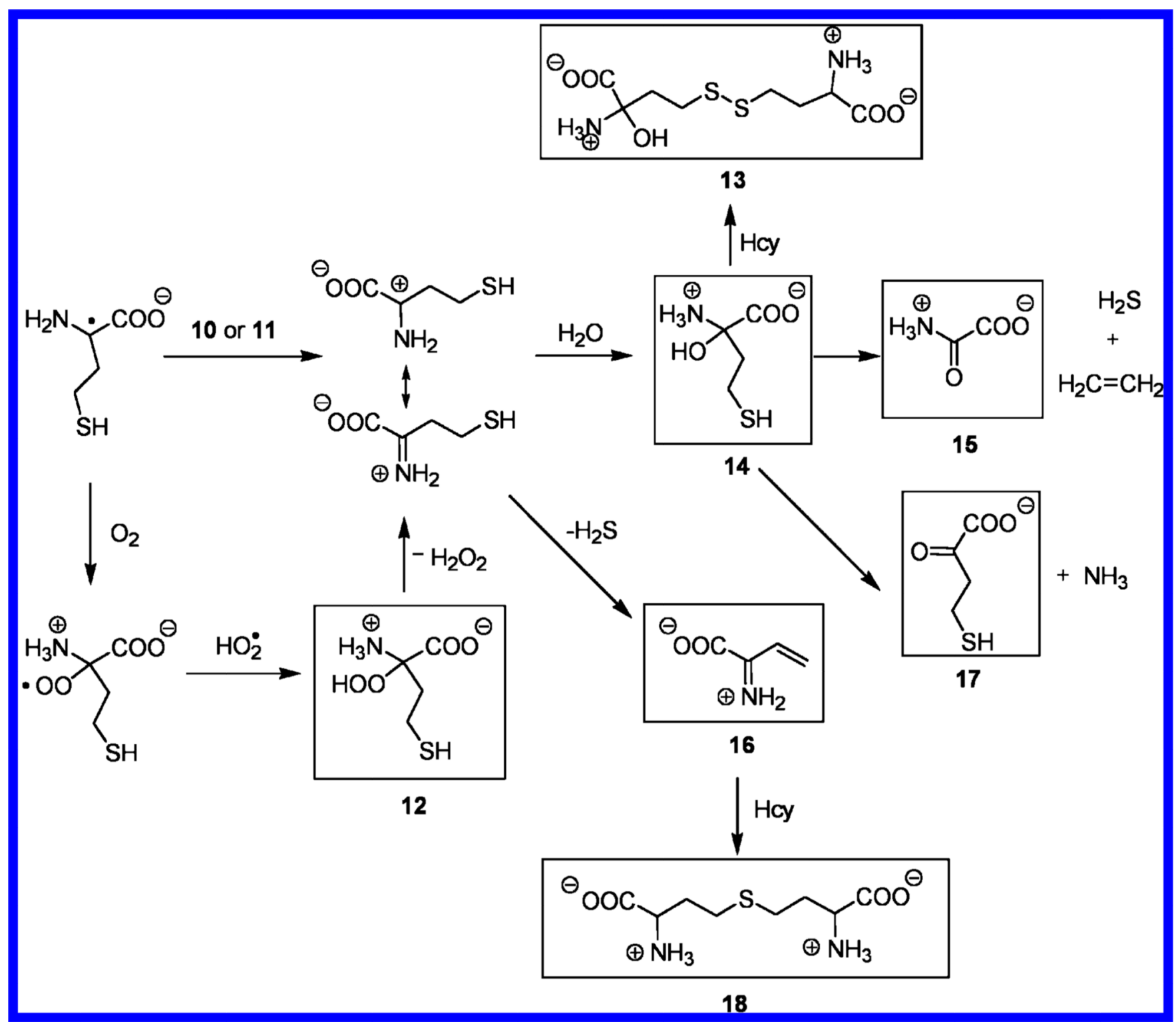

Scheme 5.

Proposed Mechanism for the Formation of Byproducts from Hcy a-Amino Carbon-Centered Radicals 
Table 1

\begin{tabular}{|c|c|}
\hline method & limitations \\
\hline monobromobimane labeling & $\begin{array}{l}\text { (i) unstable at room temperature and in } \mathrm{H}_{2} \mathrm{O} \text {; (ii) batch-to-batch varying impurity levels; (iii) fluorescent } \\
\text { hydrolysis products produced upon labeling; (iv) gradient and relatively complex elution chromatography } \\
\text { needed }\end{array}$ \\
\hline iodoacetamide labeling & $\begin{array}{l}\text { (i) cross-reactivity with histidine, tyrosine, and methionine; (ii) promotes loss of } \mathrm{NH}_{3} \text { upon reaction with Cys } \\
\text { residues; (iii) reduces mass spectrometric sensitivity }\end{array}$ \\
\hline$o$-phthalaldehyde labeling & $\begin{array}{l}\text { (i) highly } \mathrm{pH} \text { sensitive reaction; (ii) thiol adduct exhibits high photoinstability; (iii) cross-reactivity with many } \\
\text { other amino acids }\end{array}$ \\
\hline maleimide labeling & $\begin{array}{l}\text { (i) hydrolysis peaks are encountered at the beginning and end of chromatographic elution; (ii) cross-linking to } \\
\text { amines; (iii) unwanted rearrangements of conjugates }\end{array}$ \\
\hline hexaiodoplatinate labeling & broad cross-reactivity with interferences, including thioethers, thiazolidines and ascorbic acid \\
\hline
\end{tabular}


Table 2a

\begin{tabular}{|c|c|c|c|}
\hline Product & Calcd. & Found & MALDI Matrix \\
\hline & 360.53 & 359.02 & none \\
\hline & 190.28 & $\begin{array}{l}190.05 \\
191.01\end{array}$ & $\begin{array}{l}\text { Anthracene } \\
\text { Dithranol }\end{array}$ \\
\hline & 112.04 & 112.52 & none \\
\hline & 156.14 & $\begin{array}{l}156.68 \\
155.28\end{array}$ & $\begin{array}{c}\text { None } \\
\text { Dithranol }\end{array}$ \\
\hline & 138.19 & 138.23 & Dithranol \\
\hline $\mathrm{NaOOC}_{\odot \mathrm{OH}_{3}} \mathrm{~S} \overbrace{\text { OI }}$ & 282.06 & 283.33 & Anthracene \\
\hline $\mathrm{HS}^{\mathrm{S}}$ & 190.17 & $\begin{array}{l}190.05 \\
191.01\end{array}$ & $\begin{array}{c}\text { Anthracene } \\
\text { Dithranol }\end{array}$ \\
\hline & 206.28 & 205.20 & Anthracene \\
\hline
\end{tabular}

a The products highlighted in Scheme 5 have been identified by MALDI MS. They are formed under mild conditions: neutral buffer solution in the presence of $\mathbf{1 1}$ at room temperature. 